\title{
Experimental Study of Fracturing Fluid Retention in Rough Fractures
}

\author{
Yanjun Zhang, ${ }^{1,2}$ Hongkui Ge ${ }^{1 D},{ }^{1,2}$ Guangyu Liu, ${ }^{3}$ Yinghao Shen $\mathbb{D D}^{1,2}$ Hao Chen, ${ }^{1,2}$ \\ Jianbo Wang, ${ }^{1,2}$ Dunqing Liu, ${ }^{1,2}$ and Zehui Huang ${ }^{1,2}$ \\ ${ }^{1}$ State Key Laboratory of Petroleum Resources and Prospecting, China University of Petroleum, Beijing 102249, China \\ ${ }^{2}$ Unconventional Natural Gas Institute, China University of Petroleum, Beijing 102249, China \\ ${ }^{3}$ PetroChina Jilin Oilfield Company, Songyuan, Jilin 138000, China
}

Correspondence should be addressed to Hongkui Ge; gehongkui@163.com

Received 21 November 2018; Revised 17 February 2019; Accepted 12 March 2019; Published 22 April 2019

Guest Editor: Fengshou Zhang

Copyright ( 2019 Yanjun Zhang et al. This is an open access article distributed under the Creative Commons Attribution License, which permits unrestricted use, distribution, and reproduction in any medium, provided the original work is properly cited.

\begin{abstract}
Multistage hydraulic fracturing is a key technology for developing tight reservoirs. Field data indicate that a small fraction of the injected water can be recovered during flowback. Fractures play an important role in the retention of fracturing fluid, but the mechanisms and rules remain uncertain. Therefore, an experimental facility was established for studying the fluid retention in fractures using an improved conductivity apparatus. The fluid trapped in rough fractures was measured, and the dynamic changes of the drainage volume and rate under various apertures were analyzed. The effects of different factors, such as the fracture aperture, surface roughness, tortuosity, and matrix imbibition, on the fluid retention were studied. An empirical formula between the retention rate and fracture aperture was derived on the basis of mass conservation. Results showed that the fluid retention rate slowly decreased with an aperture increase in the fracture, and it would increase with considerable roughness, high tortuosity, and significant matrix imbibition. Meanwhile, drainage volume and rate change dramatically resulted from the gas drive. Secondary fractures and microcracks played an important role in the retention of fracturing fluid. Furthermore, the mechanisms of fracturing fluid retained in the tight reservoir, including viscous trapping and "locking" in fractures, the effect of gravity, surface-bound water film, capillary force retention, and matrix imbibition, were discussed. This study is significant for understanding the flowback rules of fracturing fluid, diagnosing fracture development, and identifying reservoir properties.
\end{abstract}

\section{Introduction}

Multistage hydraulic fracturing is a key technique for the effective exploitation of tight reservoirs. In the process of multistage hydraulic fracturing, a large amount of fracturing fluid is injected into the formation. However, field data show that the flowback rate of the fracturing fluid after fracturing is generally no higher than $30 \%$ [1]. For conventional reservoir hydraulic fracturing, the flowback rate should be higher to reduce the damage caused by the external fluids to the reservoir [2-4]. Nevertheless, the relationship between the flowback rate and the stimulated effect in tight reservoirs is unclear, and the production from wells with high flowback rates is unnecessarily high. The retained fracturing fluid is closely related to reservoir damage, environmental protection, and oil and gas production [5-8].

During the hydraulic fracturing, a part of retained fracturing fluid is imbibed into the matrix, and another portion is trapped in the fracture. Published studies have suggested that fracturing fluid enters the matrix by capillary force and gradually spreads to the deep matrix, which is influenced by rock composition, mineral content, porosity, permeability, wettability, geochemical characteristics, and liquid properties [9-11]. For example, the spontaneous imbibition of marine and continental shale shows that the imbibition capacity of marine shale is stronger than that of continental shale due to the difference of clay mineral content and wettability [12]. However, some researchers mentioned that only a few fracturing fluids can enter the shale matrix given the change 
TABLE 1: Classification criteria of fractures.

\begin{tabular}{lccc}
\hline Type & Aperture & Characteristic & Connectivity \\
\hline Primary fracture & $>0.80 \mathrm{~mm}$ & Single, large aperture, main flow channel & Excellent conductivity \\
Secondary fracture & $0.25-0.80 \mathrm{~mm}$ & Large number, small aperture & Good connectivity with primary fracture \\
Microcrack & $<0.25 \mathrm{~mm}$ & Discrete distribution, small scale & Poor connectivity \\
\hline
\end{tabular}

TABLE 2: Sample properties.

\begin{tabular}{lcccc}
\hline Basin & Formation & Depositional environment & Porosity (\%) & Permeability $(\mathrm{mD})$ \\
\hline Sichuan Basin & Silurian Formation & Marine deposition & 5.56 & $0.7 \times 10^{-3}$ \\
\hline
\end{tabular}

in pressure gradient during fracturing and flowback. The fracturing fluid, which is similar to proppants in the fracture, could support some closure fractures [13]. Some studies have also found that the fracturing fluid cannot flow back in time during the rapid closure of an unpropped fracture [14].

Realizing fracture characteristics is a prerequisite to studying the retention of fracturing fluid in fractures. A single rough fracture is the basic unit that comprises a fracture network. Many studies have been conducted on the description methods of rough fracture surfaces and the fluid flow rules in fractures [15-18]. In the published study, fracture aperture, surface roughness, and tortuosity are important parameters in describing fracture characteristics. However, no uniform standard exists for describing the characteristics of rough fractures. In the publications of numerical simulation, a discrete fracture network model has been established, and fracture length, density, and connectivity have been studied. Enhancing the contact between the matrix and the fracture can improve the capability of the fracturing fluid to enter the matrix [19]. The flowback rate may decrease with a complex fracture network and a large stimulated volume. So far, this phenomenon cannot be explained clearly from the level of mechanisms.

Some works have given their views on the retention mechanism of fracturing fluid by laboratory experiments, numerical simulations, and field data analysis [20-22]. A numerical simulation study shows that matrix imbibition, secondary fracture trapping, and shut-in time significantly affect production due to fluid retention [19]. The fracture closure and gravity in the primary fracture are the main mechanisms of FFR [23]. Experimental results show that the surface tension and wetting in primary fractures influence FFR, while gas displaces liquid during flowback. Meanwhile, the effect of gravity separation in a primary fracture on the fracturing fluid is significant [20]. Until now, there have been few studies on the mechanism of FFR.

The mechanism and rule of retention in rough fractures are unclear, and the relationship between the flowback rate and development of artificial fractures is uncertain. Few experimental methods have been conducted to simulate the fluid retention process. In this study, we built an experimental facility to evaluate fluid retention. The fluid trapped in rough fractures was measured, and dynamic changes in drainage volume and rate under various apertures were analyzed. The effects of different factors, such as the fracture aperture, surface roughness, tortuosity, and fracture surface imbibition, on fluid retention were studied, and the retention rate was calculated on the basis of mass conservation.

\section{Classification of Fractures}

A complex fracture network that consists of a single rough fracture is formed during multistage hydraulic fracturing. Previous studies related to hydraulic fracturing have divided fractures into primary and secondary fractures [24, 25]. For further study, fractures are divided into three types, namely, primary fractures, secondary fractures, and microcracks according to the customary method and the characteristics of various man-made fractures $[26,27]$. The main classification characteristics of fractures are shown in Table 1.

The aperture of the primary fracture is greater than $0.80 \mathrm{~mm}$. The fracture has a large opening, which is the main flow channel of the fluid, and has high conductivity. The aperture of the secondary fracture is between 0.25 and $0.80 \mathrm{~mm}$. The secondary fractures, which are minor channels of the fluid flow that have good connectivity with the primary fracture, are numerous and have small apertures. The aperture of a microcrack is less than $0.25 \mathrm{~mm}$. They distribute in a scattered state and have a small scale, which can enhance rock permeation. The primary fracture, secondary fracture, and microcrack mentioned in this paper are based on the classification criteria of fractures, as listed in Table 1.

\section{Experimental Materials and Methods}

3.1. Sample Acquisition and Characteristics. The sample was acquired from the shale outcrop $(30.00 \mathrm{~cm} \times 30.00 \mathrm{~cm} \times$ $30.00 \mathrm{~cm}$ ) of the Silurian Formation, a marine deposit in the Sichuan Basin of Southeastern Chongqing. Sample properties of the standard cores are listed in Table 2. The average porosity, measured by a helium porosity measurement device, is $5.56 \%$. The average permeability, measured by a steady-state method, is $0.0007 \mathrm{mD}$ (SY/T5336-2006). $\mathrm{X}$-ray diffraction analysis results of the shale mineral composition are shown in Table 3 . The clay mineral content is $14.5 \%-40.2 \%$, the quartz content is $38.0 \%-54 \%$, the feldspar content is $5.6 \%-12.1 \%$, and the carbonate rock content is $4.2 \%-16.0 \%$. Scanning electron microscopy images showed 
TABLe 3: Mineral composition.

\begin{tabular}{lcccc}
\hline Mineral type & Clay & Quartz & Feldspar & Carbonate \\
Mass percentage & $14.5 \%-40.2 \%$ & $38.0 \%-54.0 \%$ & $5.6 \%-12.1 \%$ & $4.2 \%-16.0 \%$ \\
\hline
\end{tabular}

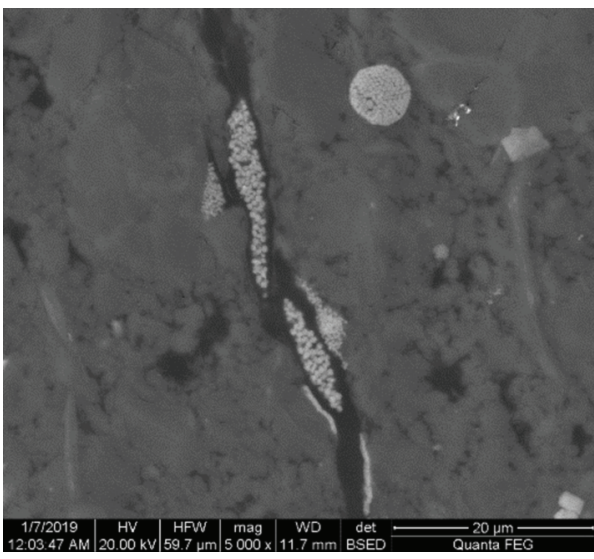

(a)

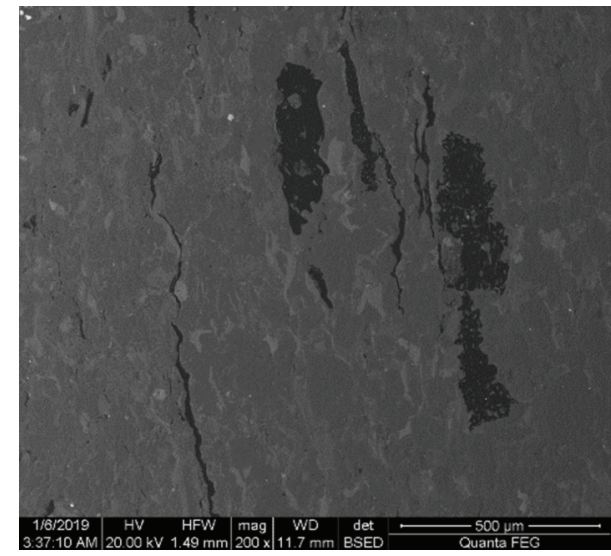

(b)

FIGURE 1: SEM images: (a) natural fracture filled with pyrite and (b) organic development.

that an organic fracture is developed and filled with pyrite, as shown in Figure 1. The elastic modulus is $20.17 \mathrm{GPa}$, Poisson's ratio is 0.28 , and the density is $2.53 \mathrm{~g} / \mathrm{cm}^{3}$.

For the convenience of research, four sets of rock samples and one group of steel samples were prepared before the experiment, and they were marked CI, CII, CIII, GHI, and GHII. The fractures of CI, CII, CIII, and GHI were formed along the bedding. GHI's fracture surface was polished by a grinder, and the fracture of GHII was formed by two steel plates. They are all shown in Figure 2. The standard cores were drilled in the direction of the vertical bedding for performing a single-sided spontaneous imbibition experiment.

3.2. Measurement of Surface Roughness. ContourGT is a three-dimensional optical microscope, which is used to obtain the roughness and surface topography of the fracture surface. The principle of white light interference was adopted for measuring the optical path difference that reflects the surface physical properties. The measuring resolution is $0.1 \mathrm{~nm}$, the measuring range is $0.1-10 \mathrm{~mm}$, and the closed loop is not stitching, as shown in Figure 3.

The surface topographies of CI, CII, CIII, GHI, and GHII were scanned using Contour-GT. The local typical morphology of the fracture surface was obtained, as shown in Figure 4 . We could thus acquire the mean square roughness $\left(R_{\mathrm{q}}\right)$, arithmetic mean deviation $\left(R_{\mathrm{a}}\right)$, and maximum height drop $\left(R_{\mathrm{v}}\right)$.

\subsection{Experimental Apparatus and Methods}

3.3.1. Experimental Apparatus. Artificial fractures have different apertures, roughness, and surface properties. The fracturing fluid is displaced by the gas during flowback. The flow and retention rule of fracturing fluid in rough fractures must be understood. Therefore, a retention experimental facility was built for studying the effects of fractures between two test samples on fluid retention. The experimental setup includes a modified conductivity apparatus and a spontaneous imbibition device, as shown in Figure 5. The modified conductivity apparatus consists of a conductivity room, a hydraulic pump with automatic pressure control, a laser ranging sensor for measuring the fracture aperture, and a computer with SmartSeries software. The device has a maximum closure pressure of $137 \mathrm{MPa}$, the conductivity room area is $64.5 \mathrm{~cm}^{2}$, and the fracture aperture-controlling accuracy is $0.1 \mathrm{~mm}$. The spontaneous imbibition device is composed of an electronic balance, a constant-temperature and humidity box, and a computer with software. The accuracy of the electronic balance is $0.00001 \mathrm{~g}$; it was used to obtain the value of matrix imbibition mass for calculating the retention rate.

3.3.2. Experimental Methods. The surface morphology of the samples was scanned before the experiment for determining surface roughness and three-dimensional topography. The experimental setup established using the conductivity apparatus was used for liquid loading and gas displacing, as shown in Figure 6(a) (the green pipeline is the gas-displacing system and the blue pipeline is the liquid-loading system). Figure 6(b) shows the placement of the specimen inside the testing cell, orientation of the fracture, and fluid flow/ drainage direction. Distilled water was used, and its volume flow rate was $5 \mathrm{~mL} / \mathrm{min}$. Nitrogen was also used, and its volume flow rate was $10 \mathrm{~mL} / \mathrm{min}$. The change in the fracture aperture could be monitored in real time through a displacement sensor. The drainage liquid mass could be collected by the balance at the outlet. The total amount of the injected water mass could be obtained by an integral. The loading mass and retention rate of fluids with different apertures, surface roughness, tortuosity, and matrix imbibition were 


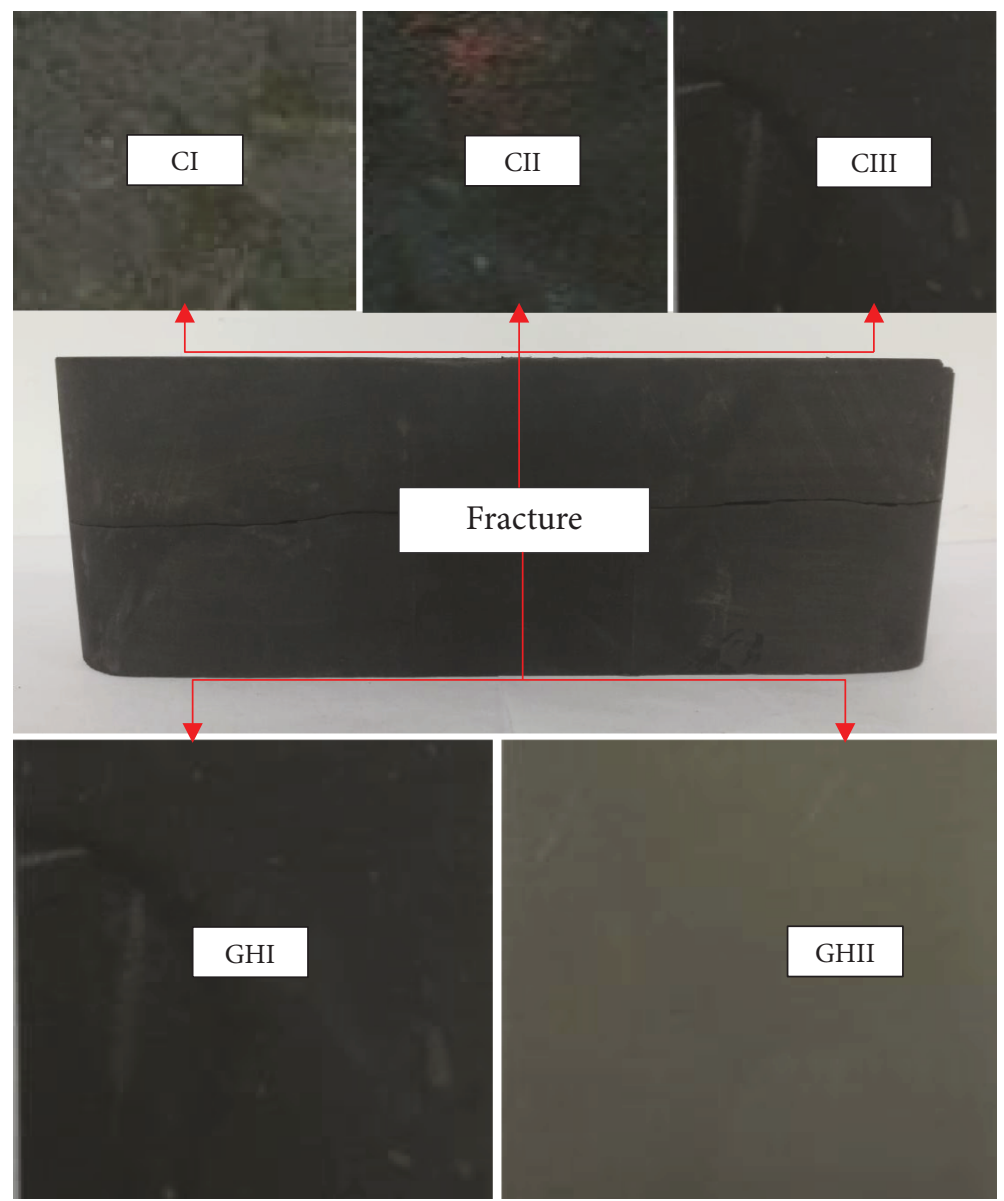

FIGURE 2: Surface characteristics of samples, four sets of test samples, and one group of steel samples (top view).

obtained. A one-sided spontaneous imbibition experiment of the standard core was conducted to obtain the mass of the spontaneous imbibition matrix.

An experiment on fluid retention was performed in the following procedure. (1) The test sample was loaded into the conductivity room according to the industrial standard SY/T 6302-2009. (2) The device was opened, and the initial fracture aperture was set. (3) The inlet valve was opened for injecting liquid into the crack and closed after the stability of flow at the outlet for $15 \mathrm{~min}$. (4) The gas valve was opened for $30 \mathrm{~min}$ for simulating the gas displacement that would occur upon disappearance of the liquid flow at the outlet. (5) The fracture aperture was adjusted before the next cycle, and the experimental data were recorded by the computer in real time. The experimental process ended upon completion of the above steps.

\section{Experimental Results}

4.1. Characteristics of Drainage Mass and Rate. The experiment was performed using four sets of test samples and one group of steel plates by adjustment of the fracture aperture. The drainage characteristics of CI, CII, and CIII at different fracture apertures were analyzed. In Figure $7(\mathrm{a})$, the fracture apertures are $1.7,1.0,0.5$, and $0.1 \mathrm{~mm}$. The experiment was used as a basic experiment without gas drive. The mass of the drainage fluid continuously increases under the different apertures. The drainage mass of the same set of experiments decreases with the reduction in the fracture aperture. In Figures $7(\mathrm{~b})$ and $7(\mathrm{c})$, the fracture apertures are 1.6, 1.3, and $0.2 \mathrm{~mm}$. The gas drive increases the drainage mass by comparison. In Figures 7(d) and 7(e), the fracture apertures are $2.2,1.8,1.6$, and $1.3 \mathrm{~mm}$. Figures 7 (b) and $7(\mathrm{~d})$ represent the case without gas drive, whereas Figures $7(\mathrm{c})$ and $7(\mathrm{e})$ represent the case with gas drive. When the apertures are 2.2 and $1.8 \mathrm{~mm}$, the drainage mass increases and then fluctuates severely due to a gas breakthrough in the fracture. In the initial stage, the drainage mass increases rapidly, and the increase in the drainage mass gradually decreases. The gas drive increases the final mass of the drainage fluid. The drainage mass in the rear of the gas drive begins to fluctuate, which results in a certain increase in the total drainage volume.

In Figure 8(a), the fracture apertures are 1.7, 1.0, 0.5, and $0.1 \mathrm{~mm}$. The rate of the drainage fluid shows a decrease trend with time. A remarkable difference in the initial drainage rate with different apertures is observed, and the difference gradually decreases with time. In Figures $8(\mathrm{~b})$ and $8(\mathrm{c})$, the fracture apertures are 1.6, 1.3, and $0.2 \mathrm{~mm}$. The gas drive, which was conducted in Figure 8(c) but not in Figure 8(b), clearly increases the drainage rate.

In Figures $8(\mathrm{~d})$ and $8(\mathrm{e})$, the fracture apertures are 2.2, $1.8,1.6$, and $1.3 \mathrm{~mm}$. The gas drive, which was conducted in 


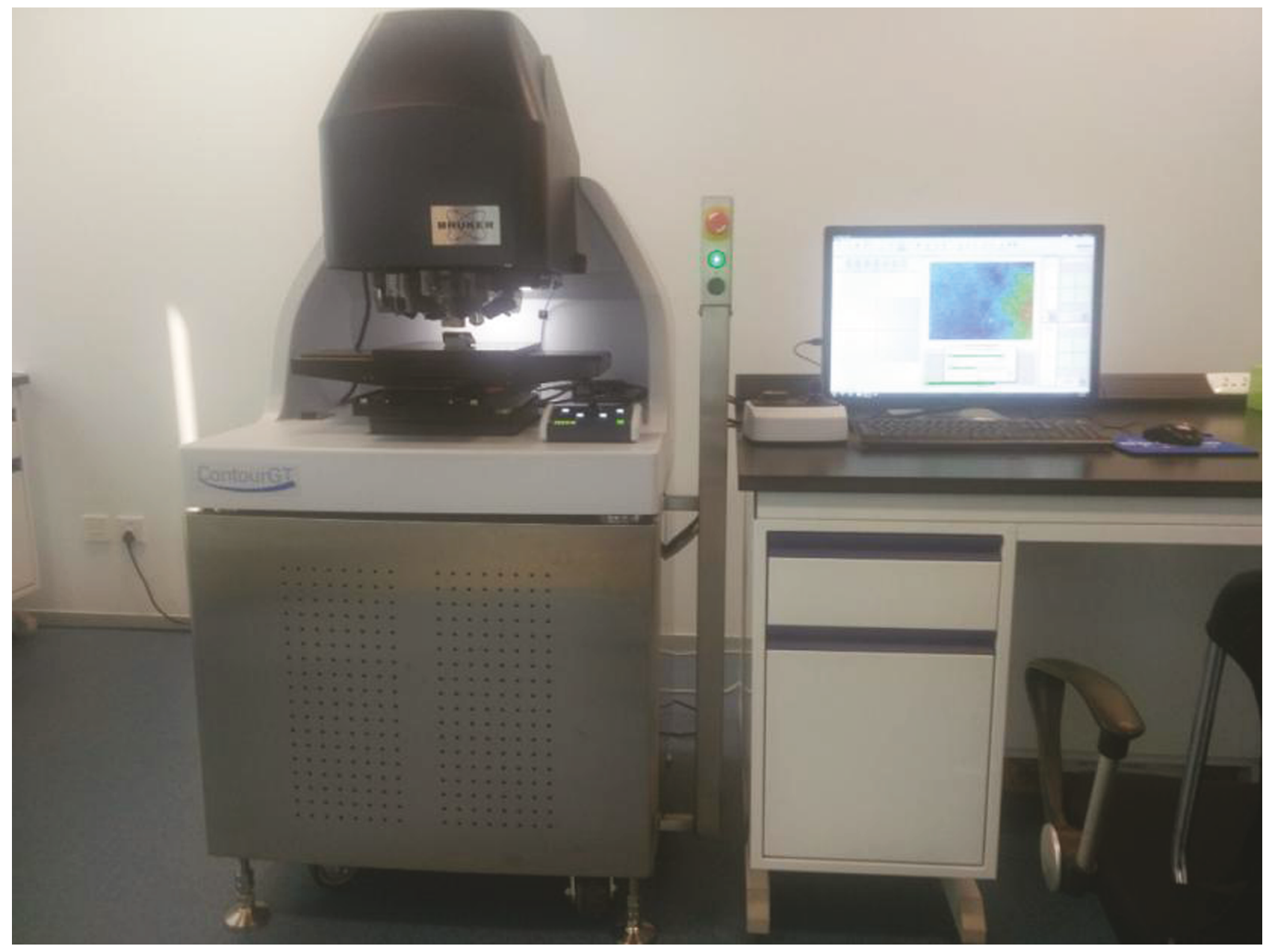

Figure 3: ContourGT.

Figure 8(e) but not in Figure 8(d), increases the rate of the drainage fluid significantly. A comparison of Figures 8 (b) and 8(c) with Figures 8(d) and 8(e) shows a noticeable difference in the drainage rate under the condition of gas displacement. The gas drive results in a sudden increase in the drainage mass and rate. This process is considered to simulate the beginning of gas production of hydraulic fracturing flowback. The characteristic of the gas-water ratio during flowback can identify the complexity of reservoir fractures. The stimulated volume was evaluated on the basis of the material balance equation [28].

4.2. Factors Affecting Liquid Retention. A large number of fractures will be generated after a tight reservoir is fractured. The fracture has different apertures, surface roughness, and tortuosity. The high imbibition capacity and adsorbed water film are caused by a large number of micro-nanopores, rich clay content, and a large stimulated area, which are not found in conventional reservoirs. Therefore, the aperture, roughness, tortuosity, and surface imbibition are studied. According to the principle of mass conservation, the amount of injected fracturing fluid in the formation is equal to the sum of the mass of fluid discharged and retained in the fractures. The total amount of liquid injected is calculated according to the injection rate. The drainage mass after gas drive can be read directly from the outlet balance. The retention mass is equal to the difference between the total amount of the injected liquid and the collecting mass of the balance after the gas drive.

4.2.1. Aperture of the Fracture. The fracture aperture is an important parameter describing the fracture feature. It decreases with the increase in the closure stress. The true opening value is obtained by comparing the initial set value with the closure value. Five groups of experiments were carried out, including sixteen different sets of apertures. The aperture is $0.1 \mathrm{~mm}, 0.2 \mathrm{~mm}, 0.5 \mathrm{~mm}, 0.7 \mathrm{~mm}, 0.8 \mathrm{~mm}$, $1.0 \mathrm{~mm}, 1.3 \mathrm{~mm}, 1.6 \mathrm{~mm}, 1.7 \mathrm{~mm}, 1.8 \mathrm{~mm}$, and $2.2 \mathrm{~mm}$. The frequency of the fracture aperture is obtained by a statistical analysis, as shown in Figure 9. According to the classification criteria of fractures, $25 \%$ of microcracks, $25 \%$ of secondary fractures, and $50 \%$ of primary fractures are representative.

Figure 10 shows the loading mass (retention mass) of the liquid at different apertures of CI, CII, and CIII. The loading mass decreases with the increase in the aperture of the fracture. CI and CII show that the effect of aperture change on a small scale on the fluid retention is greater than that on a large scale. However, CIII shows no such obvious 


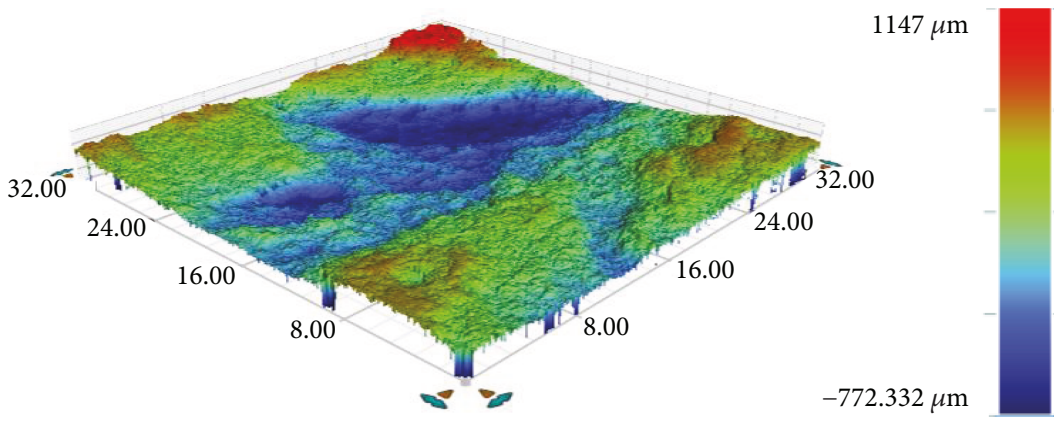

(a)

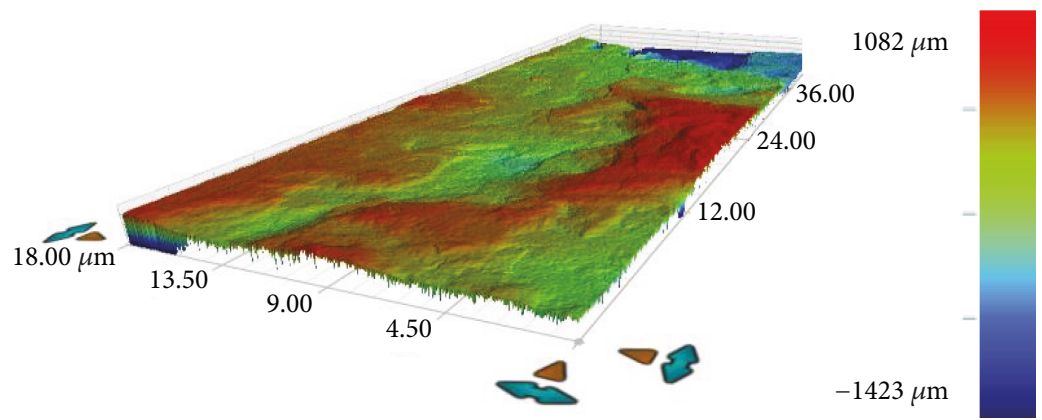

(b)

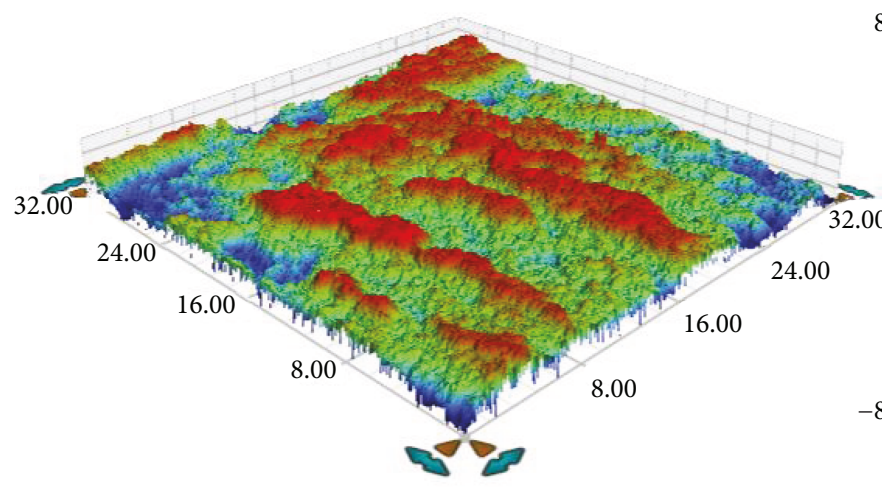

$848.913 \mu \mathrm{m}$

(c)

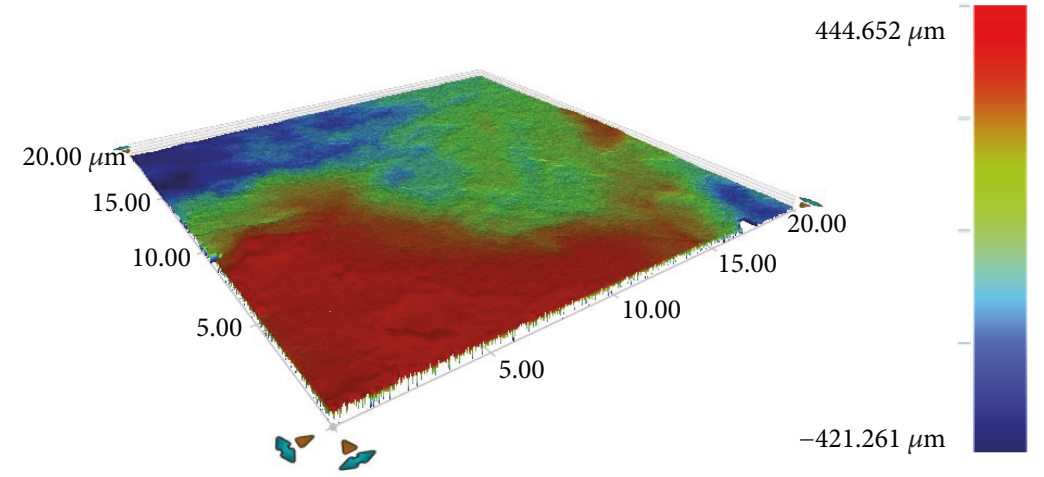

(d)

Figure 4: Continued. 

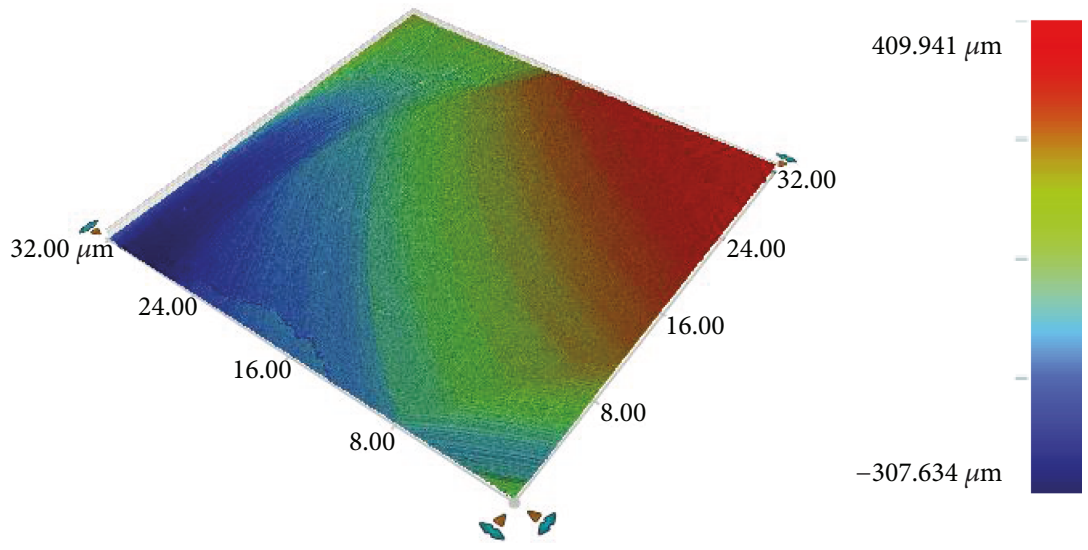

(e)

FIgURE 4: Typical morphology of the fracture surface: (a) CI, (b) CII, (c) CIII, (d) GHI, and (e) GHII.

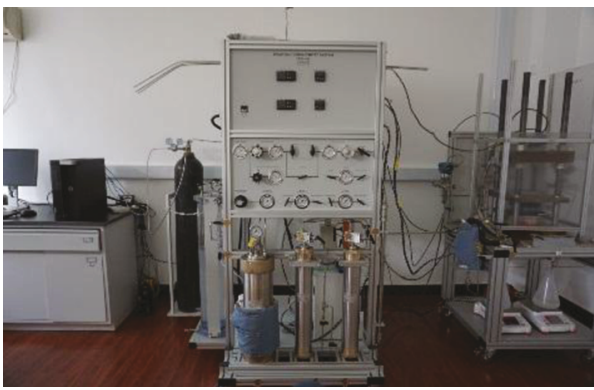

(a)

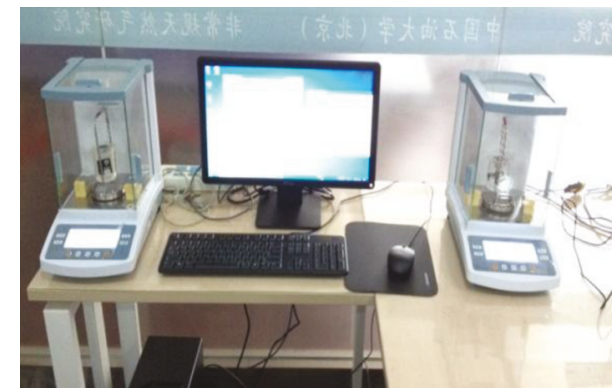

(b)

FIGURE 5: Experimental apparatus: (a) modified conductivity apparatus and (b) spontaneous imbibition device.

pattern that could be caused by gas displacement. There is some difference between gas displacement and no gas displacement. The discharge of liquid depends mainly on the elasticity of formation and liquid expansion without gas displacement [29]. The gas provides displacement pressure and increases the discharge capacity of the liquid.

4.2.2. Surface Roughness. The relevant typical morphology of the sample fracture surface is extracted, as shown in Table 4. Considering $R_{\mathrm{q}}, R_{\mathrm{a}}$, and $R_{\mathrm{v}}$, we can determine the contrast of roughness: $R_{\mathrm{CI}}>R_{\mathrm{CII}}>R_{\mathrm{CIII}}>R_{\mathrm{GHI}}>R_{\mathrm{GHII}}$. The maximum drops of CI, CII, and CIII are much larger than those of GHI and GHII. The asperity on the fracture surface determines the primary roughness, which is the first contact area with the decrease in the fracture aperture.

Different test samples have different roughness under the same aperture. When the aperture is $0.1 \mathrm{~mm}$ and $0.5 \mathrm{~mm}$, the loading mass of CI is higher than that of GHI. When the opening aperture is $0.2 \mathrm{~mm}$, the loading mass of CIII is greater than that of GHI. When the aperture is $1.6 \mathrm{~mm}$, the loading mass of CII is greater than that of CIII. High roughness leads to a large loading mass. The difference is that the loading mass of CII is lower than that of CIII when the aperture is $1.3 \mathrm{~mm}$, although the roughness of CII is higher than that of CIII.

One possible reason is that the aperture exerts a main effect on the liquid retention under large apertures, as shown in Figure 11. The primary roughness dominates the direction of the fluid flow and pressure distribution and is characterized by the maximum peak, height of the maximum peak valley, and maximum height drop. The secondary roughness was characterized by root-mean-square roughness and contour arithmetic mean square deviation, which mainly influences the distribution of the fracturing fluid in the fractures [30]. The surface roughness is an important parameter that affects the fluid flow state, and it also has a significant effect on the retention of the fracturing fluid [31, 32].

4.2.3. Fracture Tortuosity. Fractures were modeled using parallel plates in the study of fluid flow in fractures [33], as shown in Figure 12(a). The real fracture surface is rough, and the fracture formed by the rough surface has a certain tortuosity, as shown in Figure 12(b). Roughness and tortuosity affect the flow state and the regularity of fluid in fractures. The presence of tortuosity increases the flow space and the fracture surface area connected with fluid.

Tortuosity can be characterized by different methods. The simplest method for describing tortuosity is the rate of chord and arc, which is defined as the ratio of the length of the curve to the distance between the endpoints. According to the definition of tortuosity, we can obtain $\tau_{\mathrm{CI}}>\tau_{\mathrm{CII}}>\tau_{\mathrm{CIII}}>\tau_{\mathrm{GHI}} \approx \tau_{\mathrm{GHII}}$. When the aperture is $0.1 \mathrm{~mm}$, the loading mass of CI is higher than that of GHI. When the aperture is $0.2 \mathrm{~mm}$, the loading mass of CIII is 


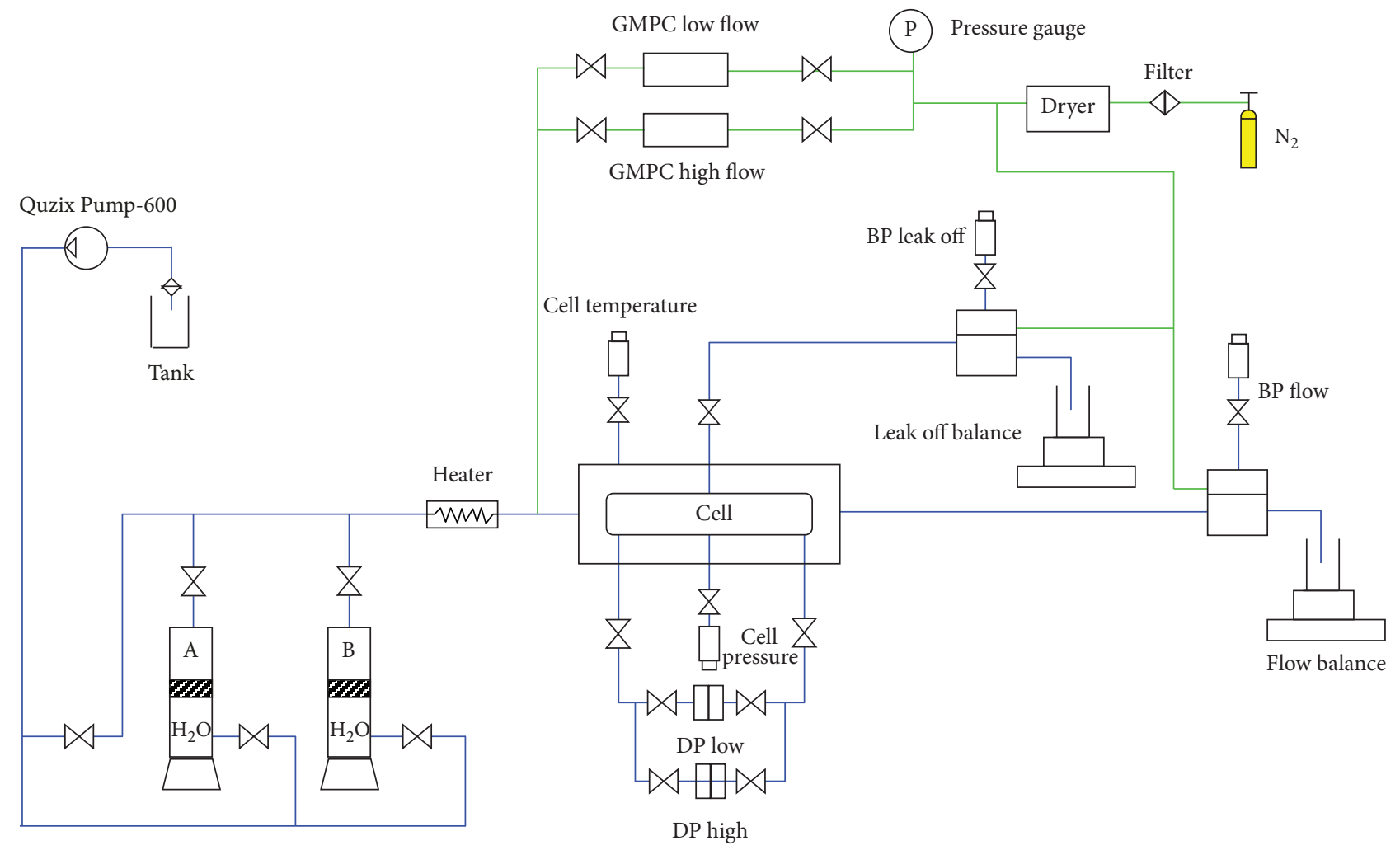

(a)

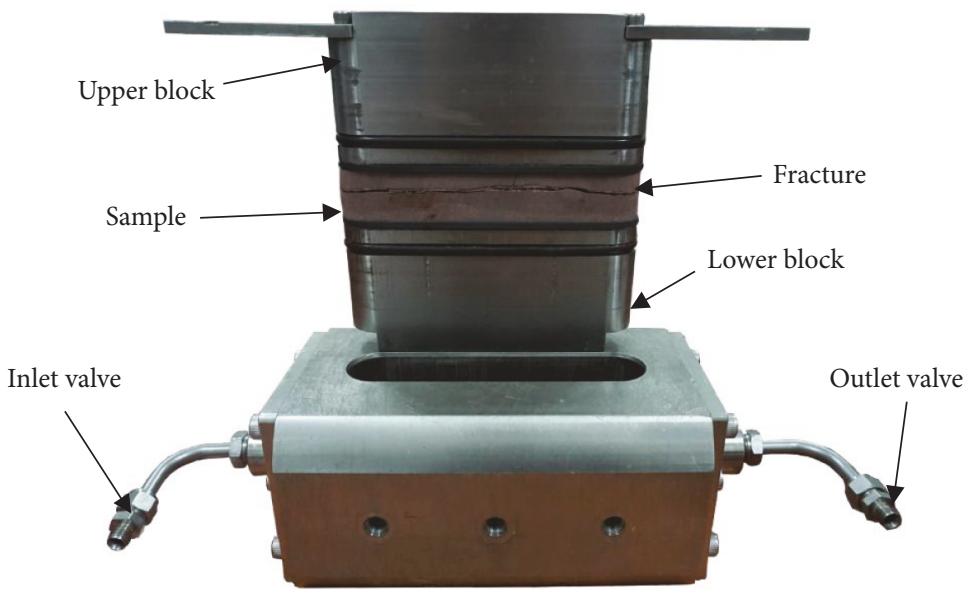

(b)

FiguRE 6: Experimental apparatus pictures. Retention (blue) and gas-displacing (green) systems: (a) sketch map and (b) physical map.

higher than that of GHI. As shown in Figure 13, the loading mass increases with great tortuosity.

4.2.4. Imbibition of the Matrix. The degree of rock dryness affects the matrix imbibition. In the process of reservoir formation, hydrocarbon drainage and vaporization occur in a tight reservoir. The high temperature and pressure conditions underground keep the water evaporating continuously, thereby resulting in the low water saturation of the rock. The fracturing fluid enters the dry reservoir under a "thirsty" state and is thus difficult to expel. A single-sided spontaneous imbibition experiment of four groups (I, II, III, and IV) was performed. The core circumference and top surface were sealed by epoxy resin to appear as a face. The sample immersed in the liquid completely was suspended from the analytical balance with a waterproof line [9]. As shown in Figure 14, we could gain the single surface spontaneous imbibition mass. And then, we calculated the single surface spontaneous imbibition mass per unit area. Finally, we would gain the imbibition mass of test samples. The special properties of the shale lead to high imbibition. However, compared with the FFR in the fracture (for example, Figure 10), the 


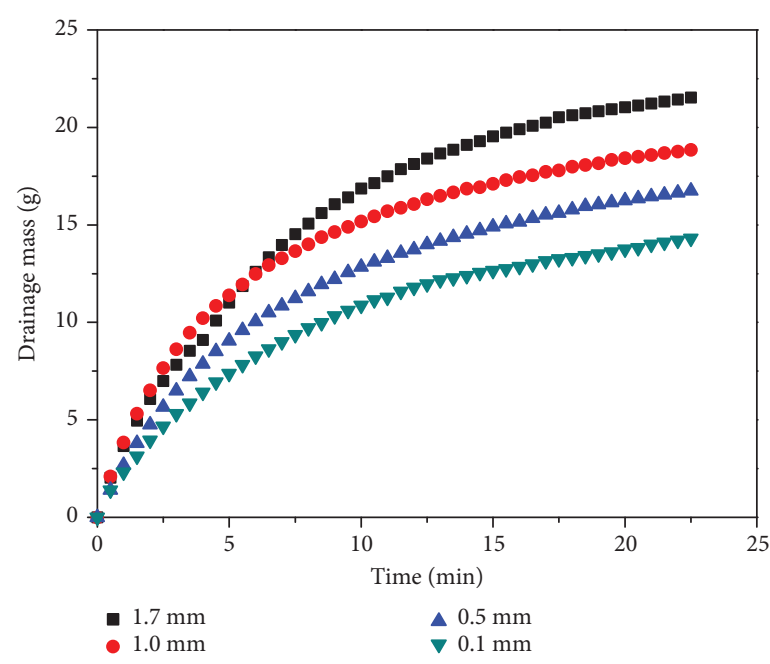

(a)

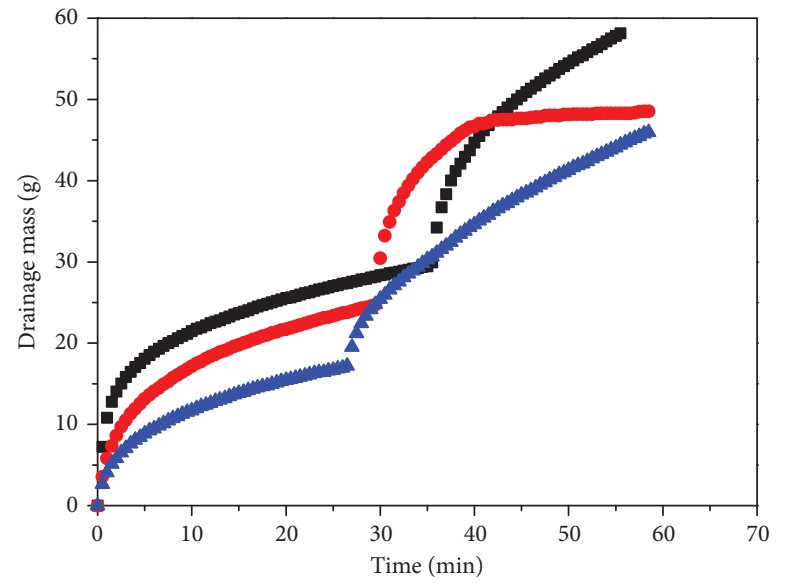

- $1.6 \mathrm{~mm}$

- $1.3 \mathrm{~mm}$

- $0.2 \mathrm{~mm}$

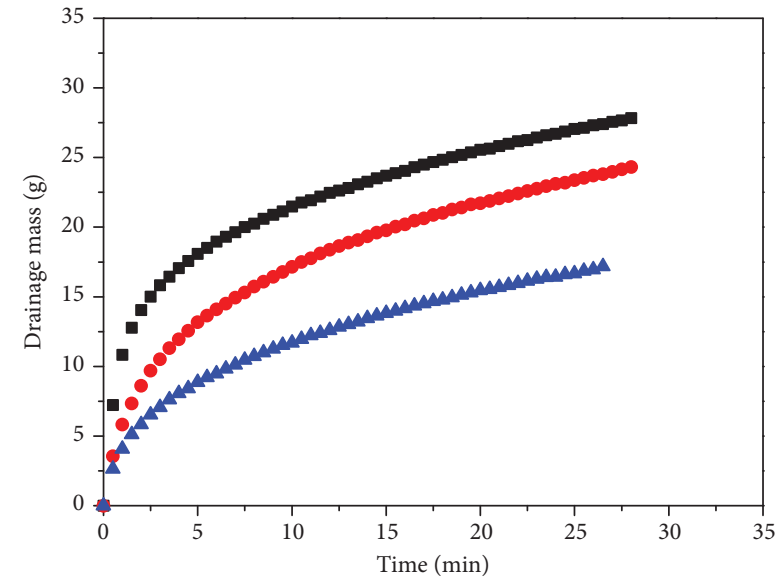

- $1.6 \mathrm{~mm}$

- $1.3 \mathrm{~mm}$

- $0.2 \mathrm{~mm}$

(b)

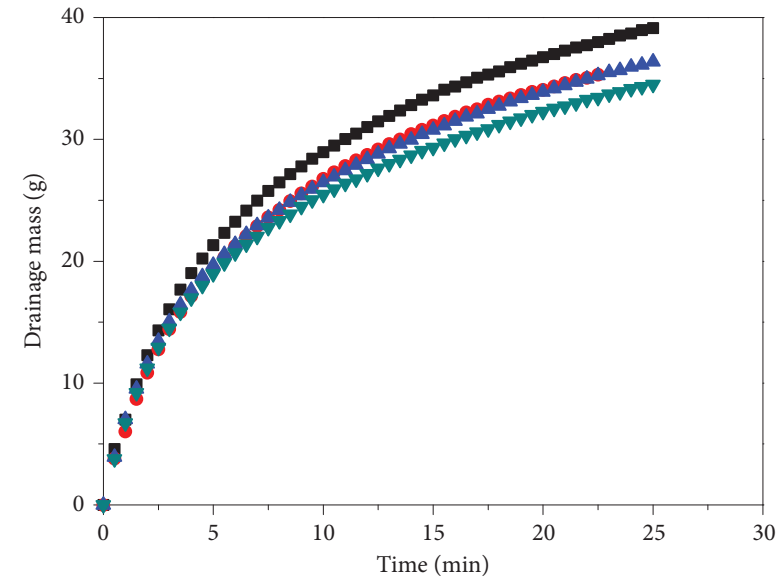

(c)

(d)

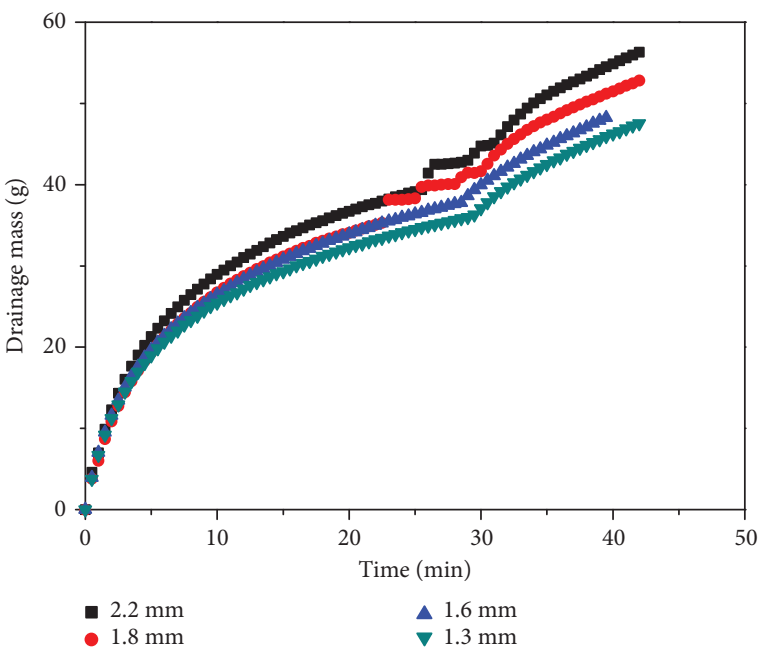

(e)

FIguRE 7: Drainage mass with different fracture apertures: (a) CI (without gas drive), (b) CII (without gas drive), (c) CII (with gas drive), (d) CIII (without gas drive), and (e) CIII (with gas drive). 


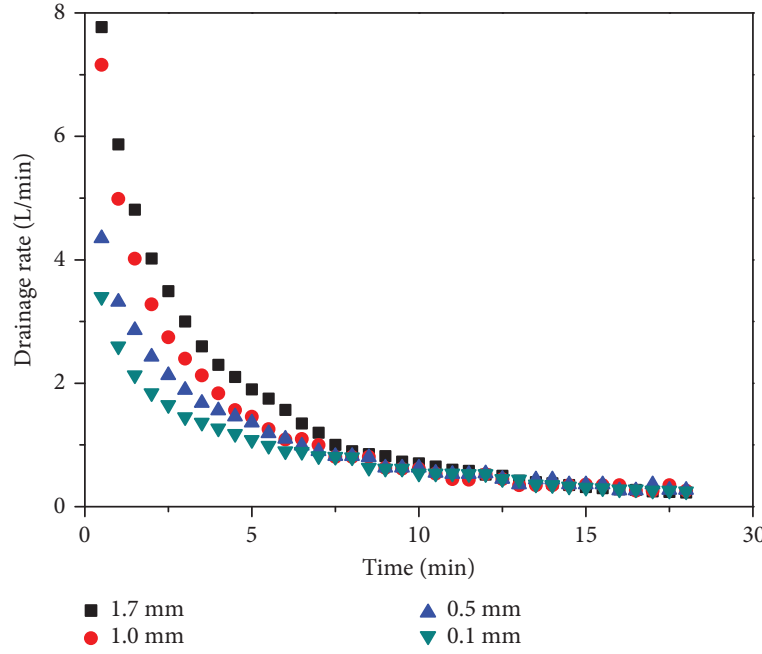

(a)

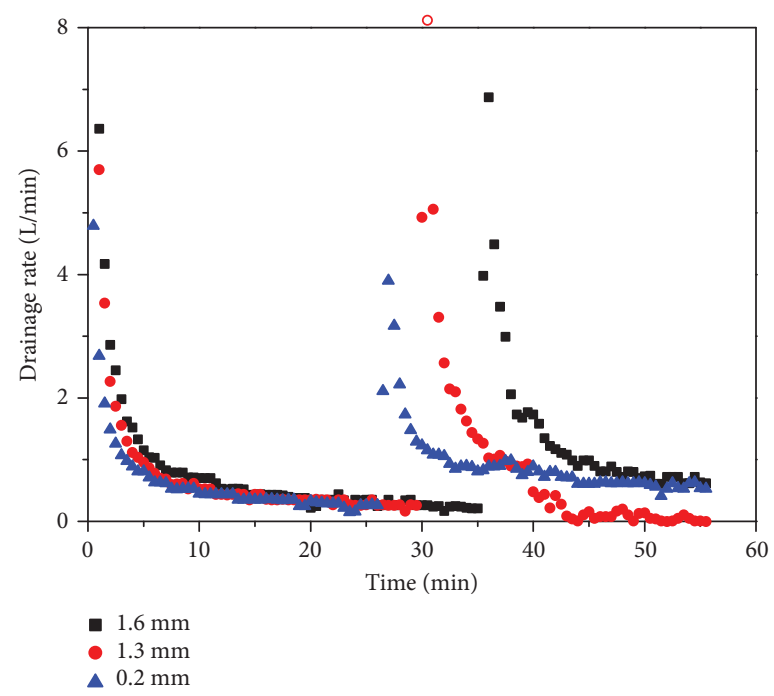

(c)

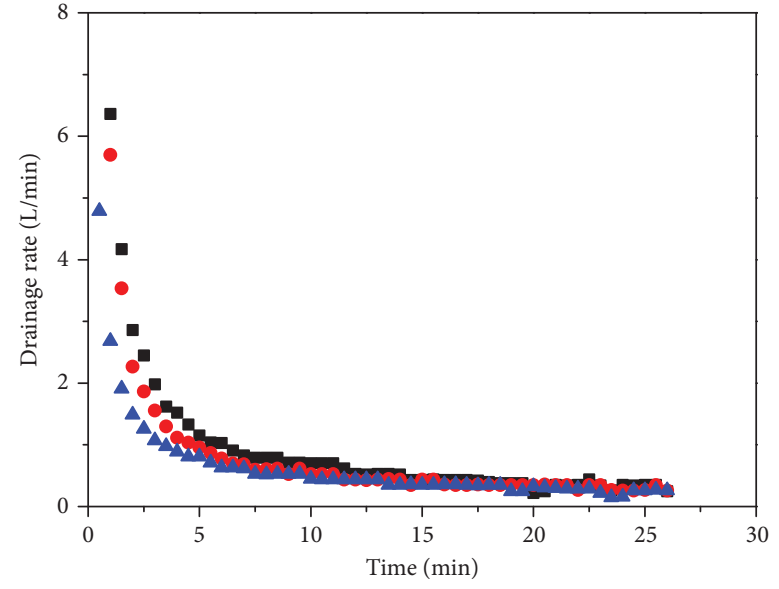

- $1.6 \mathrm{~mm}$

- $1.3 \mathrm{~mm}$

- $0.2 \mathrm{~mm}$

(b)

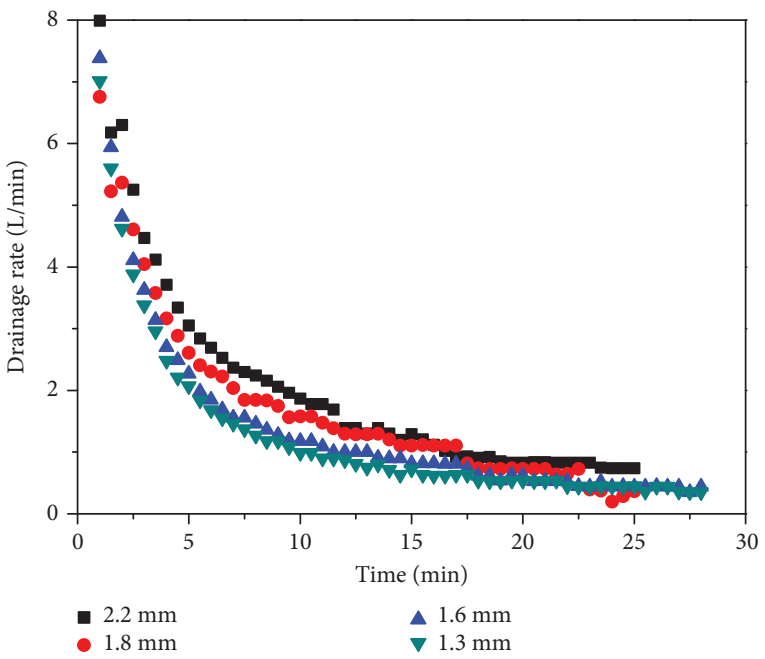

(d)

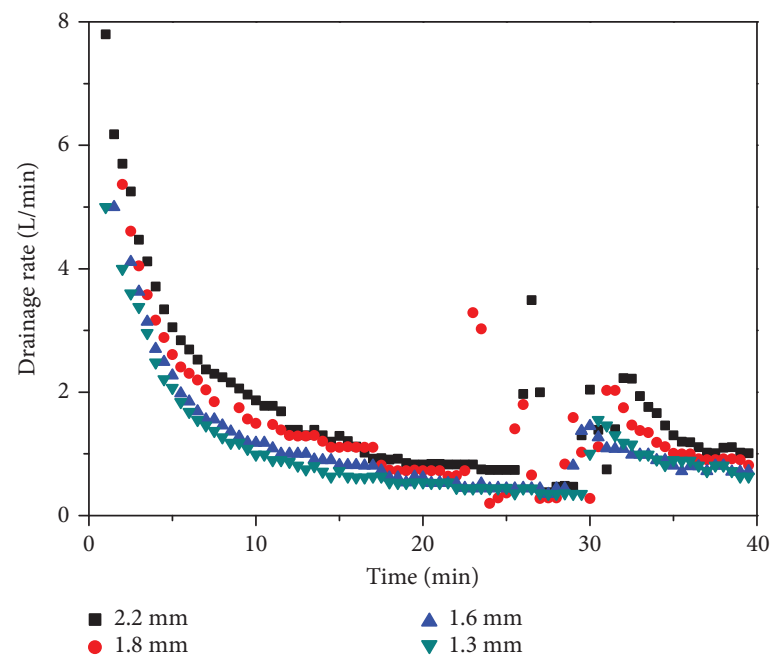

(e)

FIgURE 8: Drainage rate with different fracture apertures: (a) CI (without gas drive), (b) CII (without gas drive), (c) CII (with gas drive), (d) CIII (without gas drive), and (e) CIII (with gas drive). 


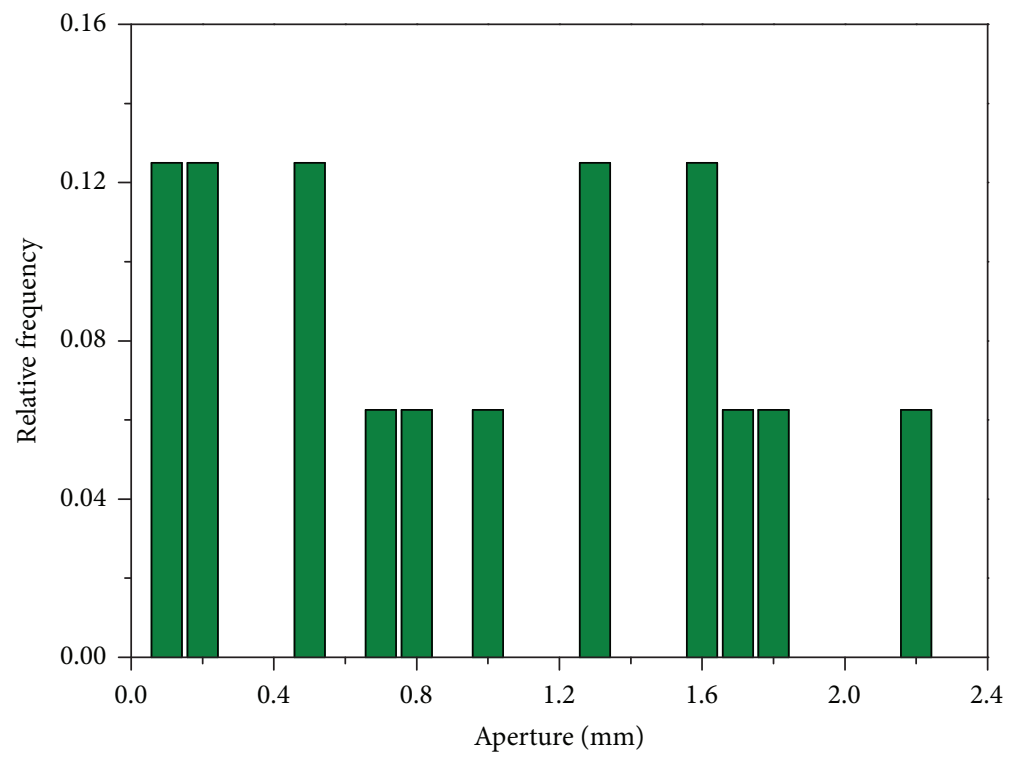

FIGURE 9: Distribution frequency of the aperture.

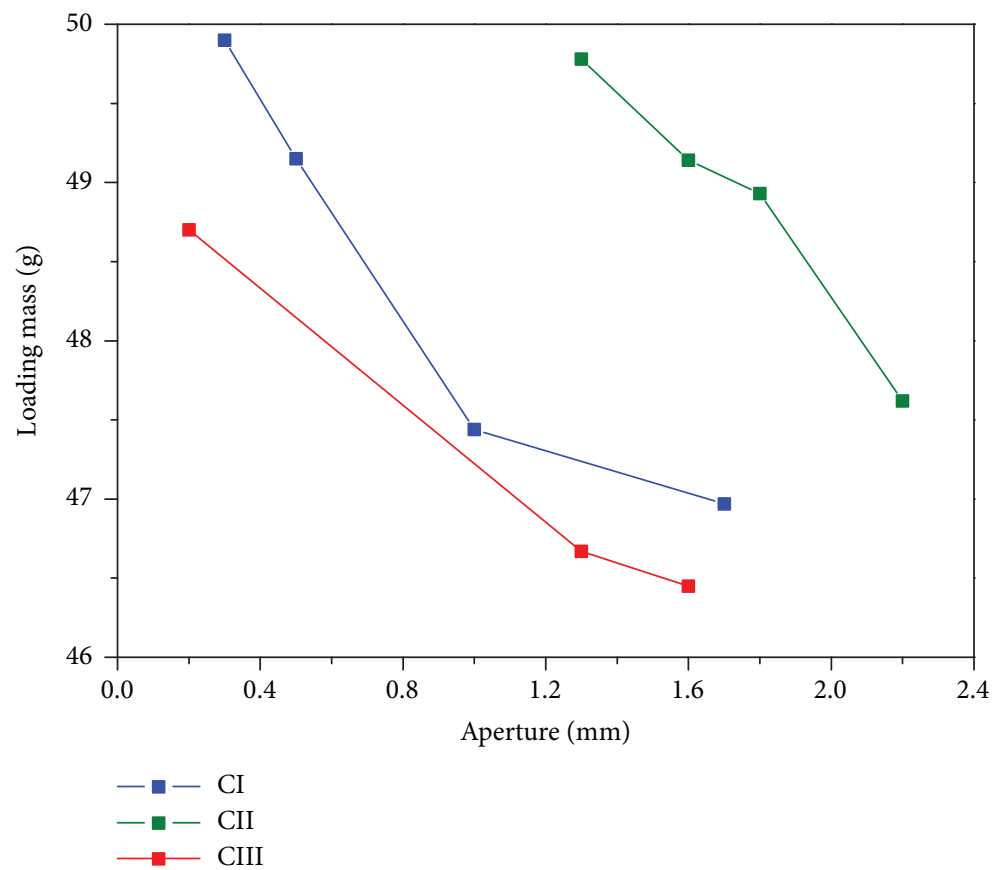

FIGURE 10: Loading mass at different apertures.

TABLE 4: Local roughness of test samples.

\begin{tabular}{lccc}
\hline Test sample name & $R_{\mathrm{a}}(\mu \mathrm{m})$ & $R_{\mathrm{q}}(\mu \mathrm{m})$ & $R_{\mathrm{v}}(\mu \mathrm{m})$ \\
\hline CI & 270.025 & 330.888 & 772.332 \\
CII & 231.824 & 286.561 & 691.251 \\
CIII & 97.358 & 117.974 & 421.261 \\
GHI & 18.589 & 26.389 & 146.435 \\
GHII & 8.953 & 7.957 & 59.837 \\
\hline
\end{tabular}

proportion of spontaneous imbibition near the fracture surface is smaller.

\section{Calculation of the Retention Rate}

According to mass conservation, the amount of the injected fluid in the formation is equal to the sum of the amount of fluid discharged and liquid retained in the fractures. The amount of liquid retained in the fractures can be decomposed 


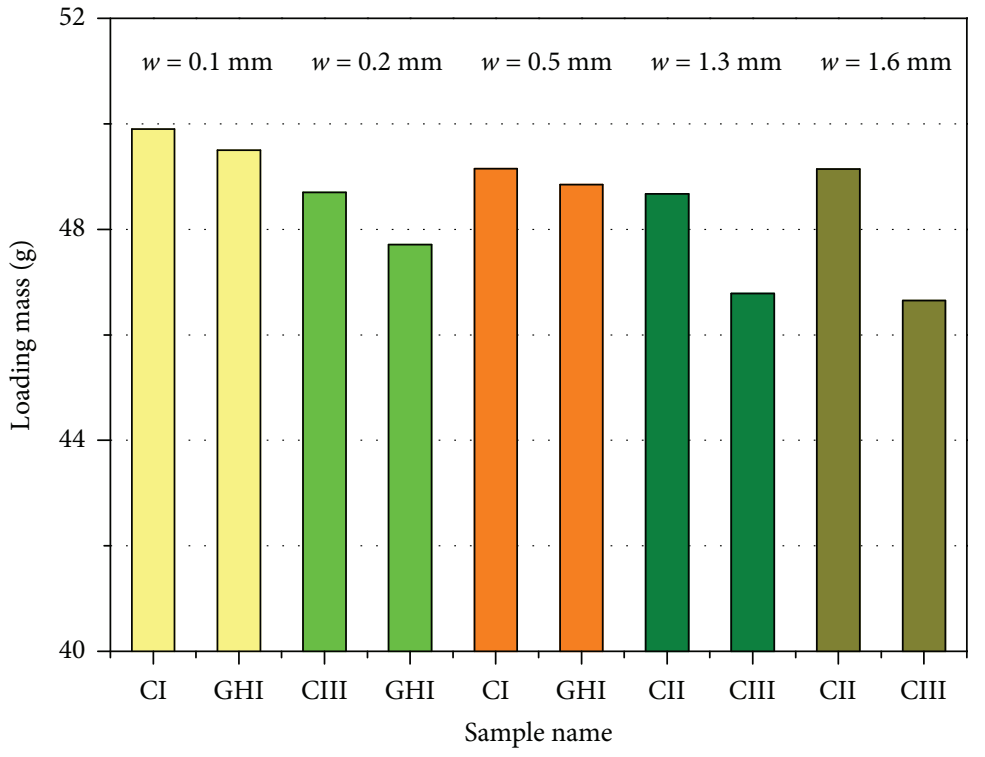

FIGURE 11: Loading mass at different roughness.

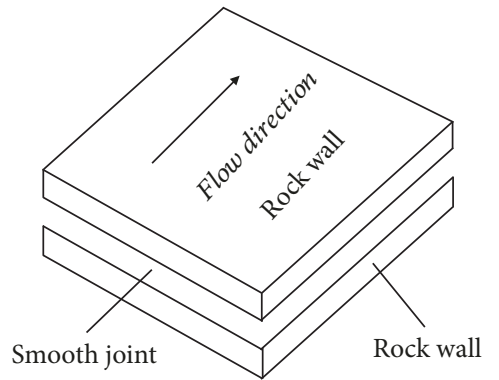

(a)

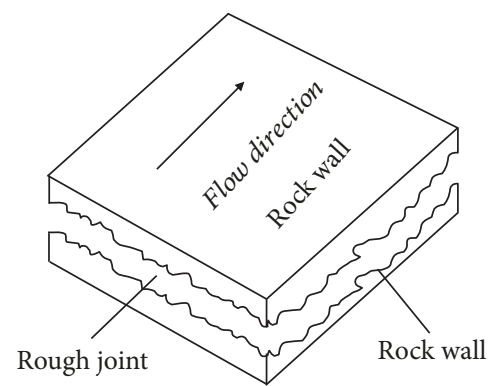

(b)

FIGURE 12: Model of fracture: (a) parallel plate model and (b) rough fracture model.

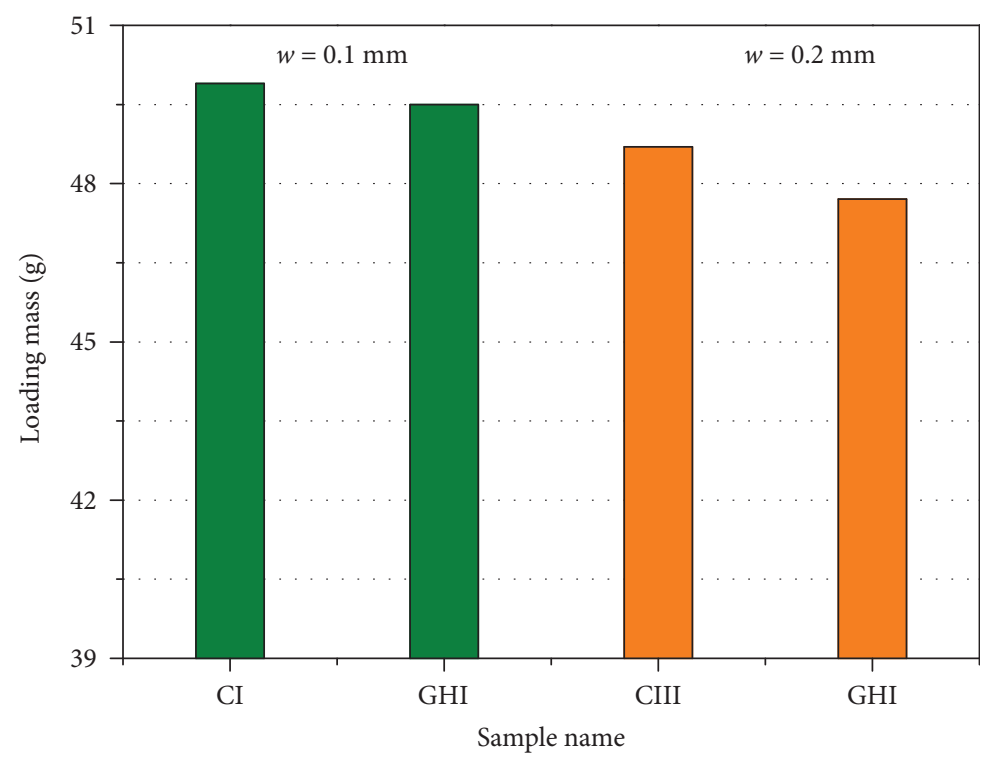

FIgURE 13: Loading mass at different tortuosity. 


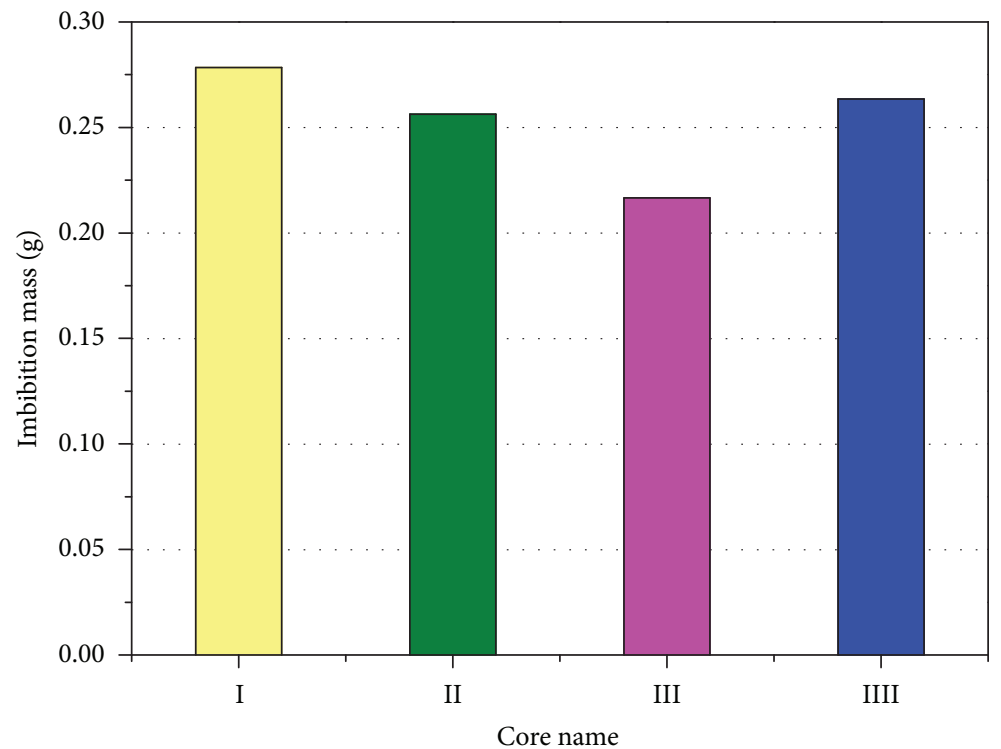

(a)

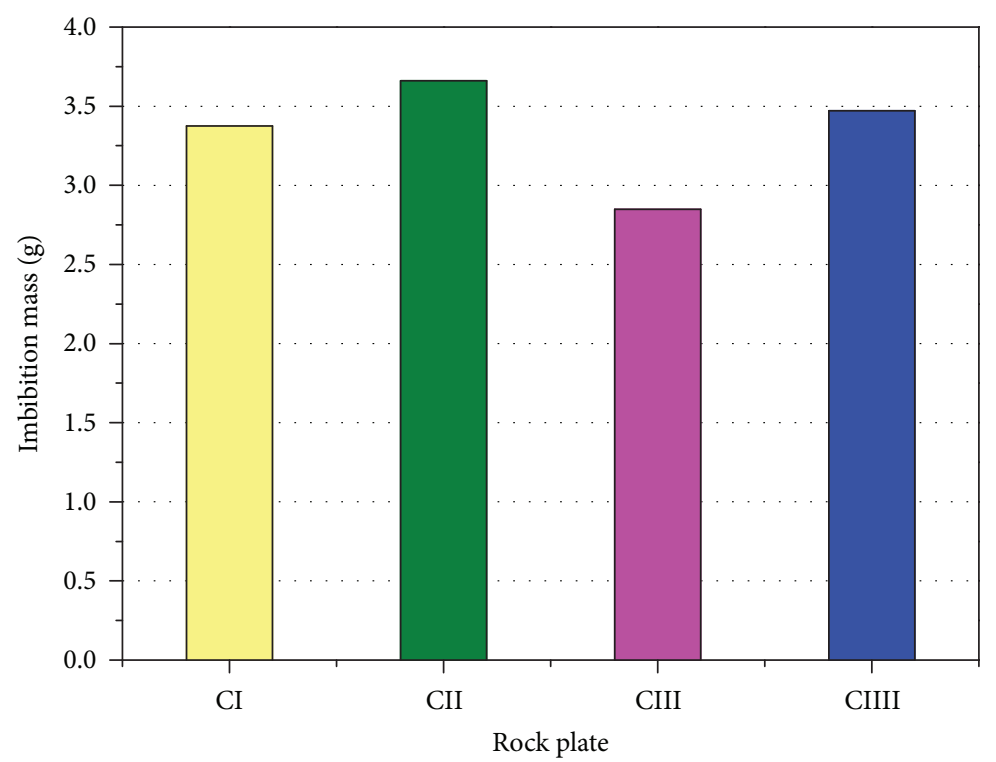

(b)

FIGURE 14: Single-sided imbibition: (a) standard rock imbibition and (b) test sample imbibition.

into matrix imbibition, surface-bound water film, capillary retention on the surface, viscous retention in the fractures, and the retention due to fracture "locking." They are described by using

$$
\sum M=M_{\mathrm{f}}+M_{\mathrm{m}}+M_{\mathrm{s}}+M_{\mathrm{c}}+M_{\mathrm{v}}+M_{1}
$$

where $\Sigma M$ is the total injection mass $(\mathrm{g}), M_{\mathrm{f}}$ is the drainage mass $(\mathrm{g}), M_{\mathrm{m}}$ is the matrix imbibition ( $\left.\mathrm{g}\right), M_{\mathrm{s}}$ is the surface-bound water film retention $(\mathrm{g}), M_{\mathrm{c}}$ is the capillary retention $(\mathrm{g}), M_{\mathrm{v}}$ is the viscous retention $(\mathrm{g})$, and $M_{\mathrm{l}}$ is the fracture "lock" retention $(\mathrm{g})$. In this study, the parameters in equation (1) can be obtained via an experiment of retention and spontaneous imbibition.

$$
R=\frac{\sum M-M_{\mathrm{f}}}{\sum M}
$$

where $R$ is the retention rate and is a dimensionless parameter. The total injection $\Sigma M$ can be obtained by integration of the pump displacement. The matrix mass after the imbibition stability is included in the numerator of (2) considering the time effect of imbibition. The retention rate of the fracturing fluid of the four groups of test 


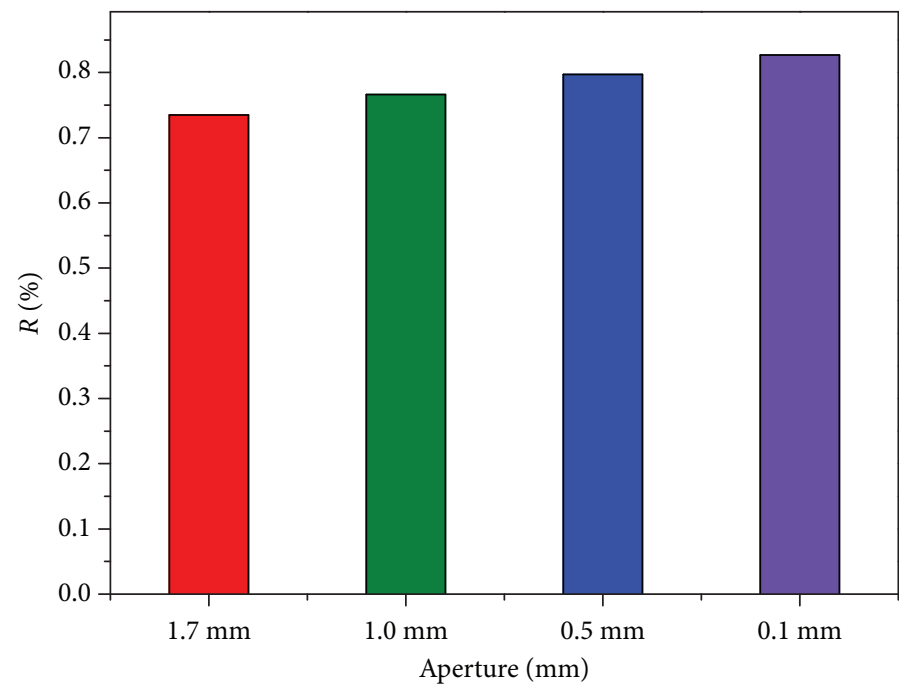

(a)

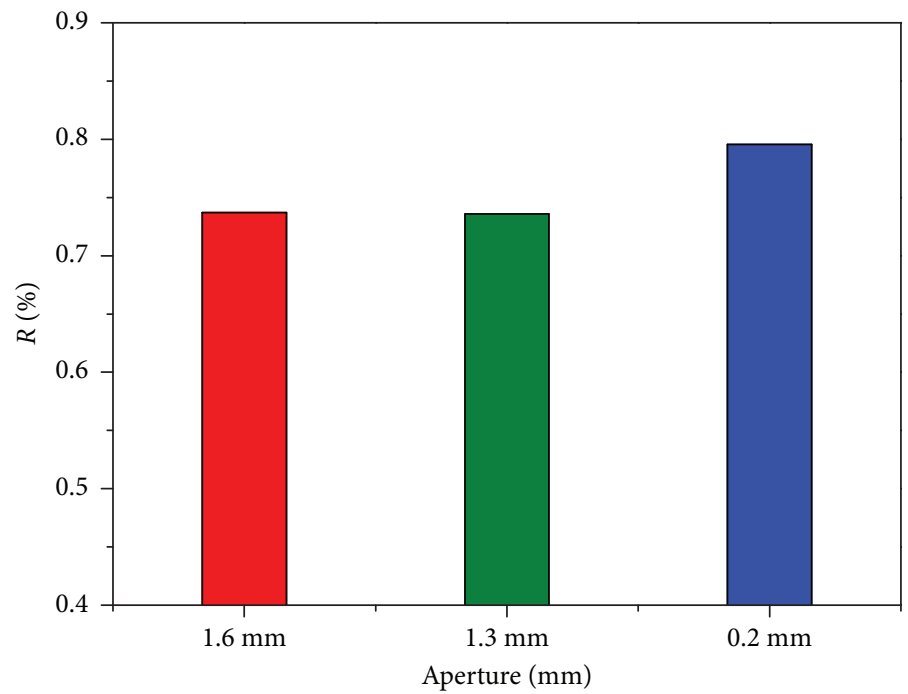

(b)

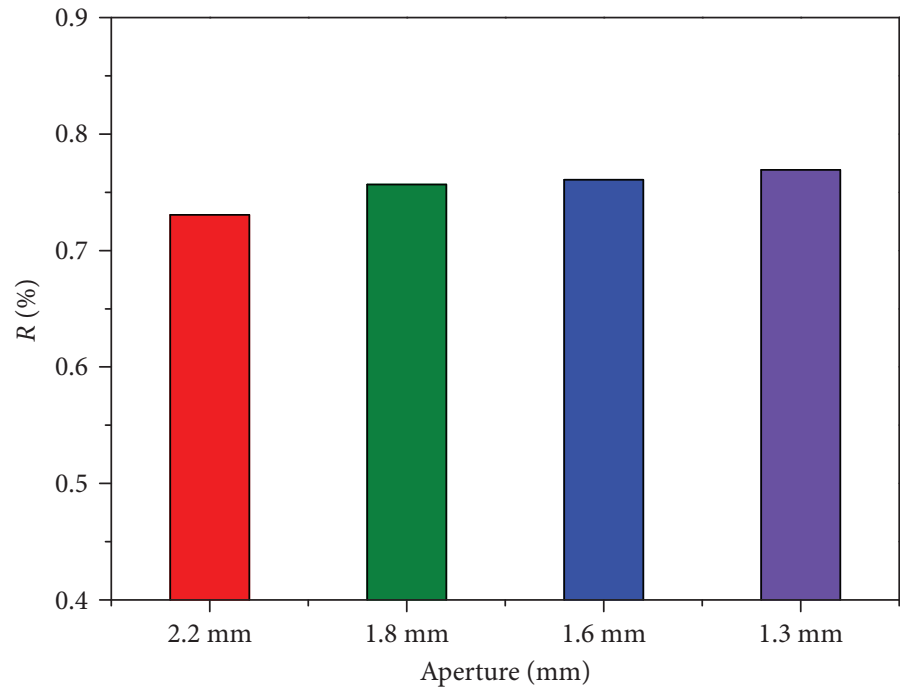

(c)

Figure 15: Continued. 


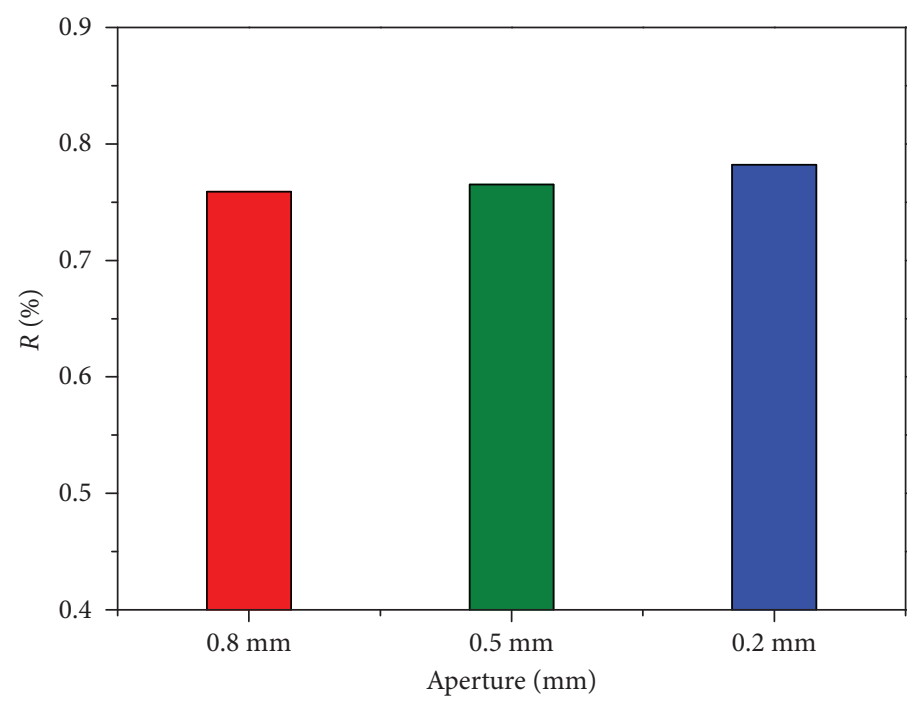

(d)

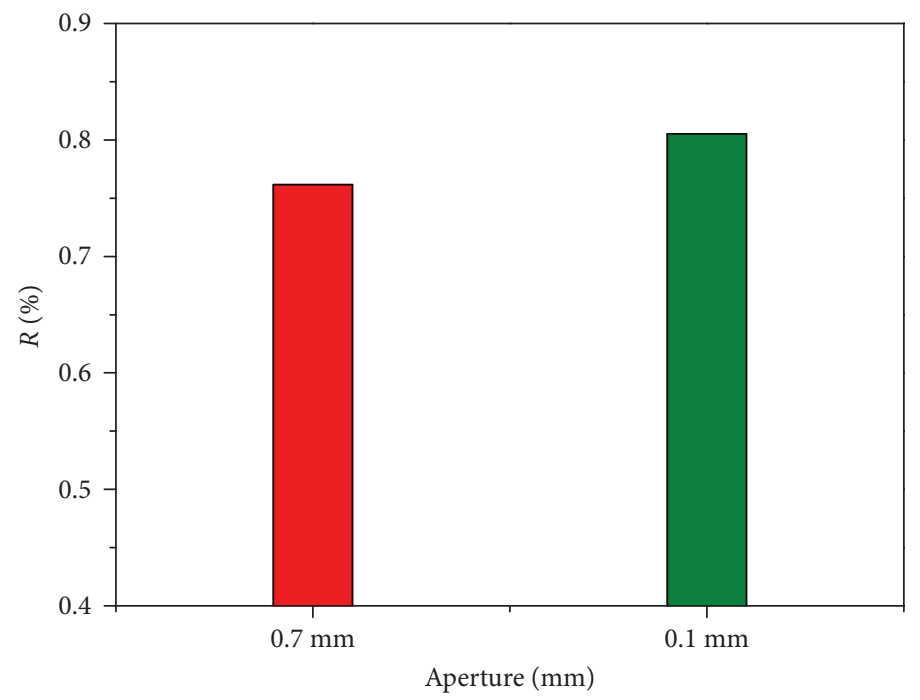

(e)

Figure 15: Retention rate at different apertures: (a) CI, (b) CII, (c) CIII, (d) GHI, and (e) GHII.

samples and a set of steel samples under different fracture apertures was obtained, as shown in Figure 15.

The retention rate decreases with the increase in aperture and maintains at $70 \%-85 \%$. The retention rate of the primary fracture is between $70 \%$ and $77 \%$, the retention rate of the secondary fracture is between $75 \%$ and $80 \%$, and the retention rate of the microcrack is between $78 \%$ and $85 \%$. A partition evaluation diagram of the FFR rate is shown in Figure 16.

Microcracks, secondary fractures, and primary fractures correspond to three related fracture zones. The retention rates of the microcrack and secondary fracture zones are higher than that of the primary fracture zone. The aperture increases from $0.1 \mathrm{~mm}$ to $2.2 \mathrm{~mm}$, and the retention rate decreases from approximately $85 \%$ to $70 \%$. The empirical formula $y=-0.024 \ln x+0.7582$ can be obtained by fitting the curve, as shown in Figure 16. The retention rates of the rough fracture are scattered on both sides of fitting line A, and the retention rates of the smooth fracture are scattered on both sides of fitting line $\mathrm{C}$. With a decrease in the aperture of the primary fracture to the secondary fracture, the asperity of the fracture surface can cause local contact and retain the fluid near the contact points.

The samples were split along the bedding, and one of them was subjected to a smooth treatment. The smooth fracture surface may be damaged in the treatment process and reduce the fracturing fluid imbibition. The dry surface and the driving pressure difference are small, and the fitting points are uniformly distributed near fitting line A. Considerable retention rate points of small fractures distribute around fitting line $\mathrm{C}$ with great tortuosity and high retention rate. Tortuosity increases the complexity of the channels, thereby requiring high pressure and energy to drain the fluid. The retention rate becomes high with small aperture, large 


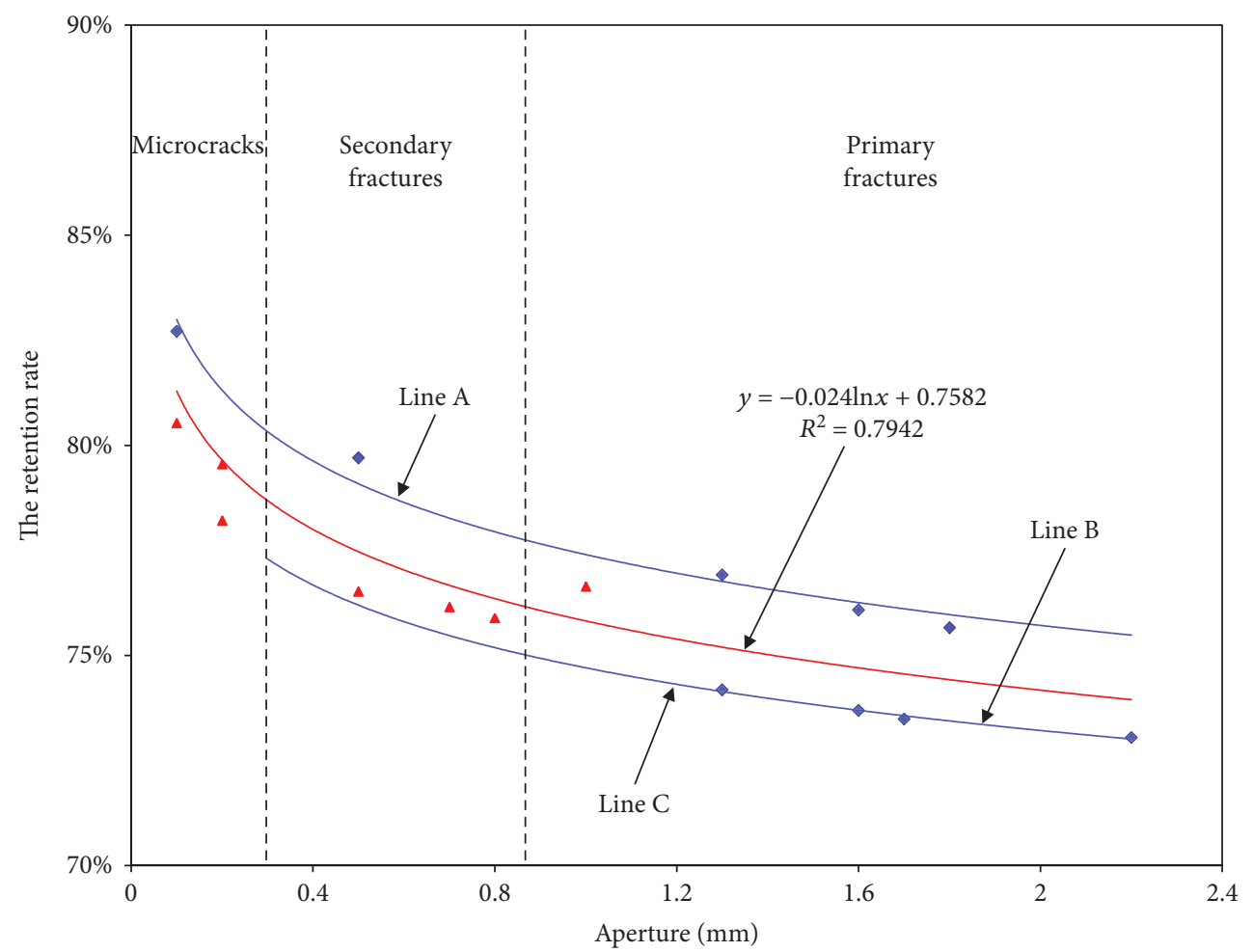

FIGURE 16: Relationship between the aperture and retention rate.

roughness, high tortuosity, and high imbibition of the matrix. Fracturing fluid is mainly trapped in fracture systems, which has different functions at various apertures. Secondary fractures and microcracks play an important role in the retention of fracturing fluid.

\section{Discussion}

6.1. Mechanisms of FFR. The retention of fracturing fluid in the rough fractures of tight reservoirs is controlled by various mechanisms. The predominant mechanism of FFR varies under different fracture geometry characteristics and reservoir properties. Experiments in this study were conducted to study the retention mechanism, including retention of the surface capillary force, irreducible water film, matrix imbibition, and viscous trapping in the fracture.

Restricted by experimental conditions, mechanisms not studied also include the gravity in the primary fracture and the "locking" in the microcrack [24]. The fluid flowback rate when the gas displacement direction is the same as the direction of gravity is greater than that opposite in the primary fracture [19]. Gravity segregation is an important mechanism that influences the retention in the primary fracture, which is affected by the fracture aperture, fracture height, and liquid viscosity. The retention rate becomes large with high fracture height, rough fracture surface, and high density of the network.

The viscous force and capillary force exert significant influences on the exchange of fluid in fractures and the matrix at low velocity. Viscous retention in the microcrack is caused by the viscous force, and capillary retention on the fracture surface is formed by the capillary force. The viscous retention has a significant effect with small aperture and pressure difference and great viscosity. The capillary retention is influenced by great roughness and water-wet reservoirs. The rock fracture surface will be covered with a layer of water film influenced by the content of clay minerals, formation water, and property of fracturing fluid. The surface-bound water film is another important mechanism of FFR impacted by the dryness and the property of the rock surface. The dry rock surface and strong hydrophilic rock are conducive to fluid retention, as shown in Figure 17.

"Locking" is defined as storage of liquids in rough fractures under the condition of a certain contact area and external pressure. A portion of the secondary fracture is partially supported by a proppant. The fracturing fluid is trapped in the fractures after the closure of fracture, as shown in Figure 18. The "locking" of fractures may be an important mechanism that improves formation energy, which can store high-pressure fracturing fluid. The "locking" is mainly controlled by the aperture, roughness, closure stress, and contact area. High roughness, local "locking," and large area of contact are conducive to the retention of the fracturing fluid.

Spontaneous imbibition is an important mechanism of fluid retention during the flowback affected by the porosity, clay minerals, surfactant, and injection fluid salinity. Micro-nanopores, high clay and ionic content, and wettability of the fluid are conducive to spontaneous imbibition $[10,12]$. The retention mechanisms of fracturing fluid are summarized according to the retention type, controlling factor, and favorable condition, as shown in Table 5. 


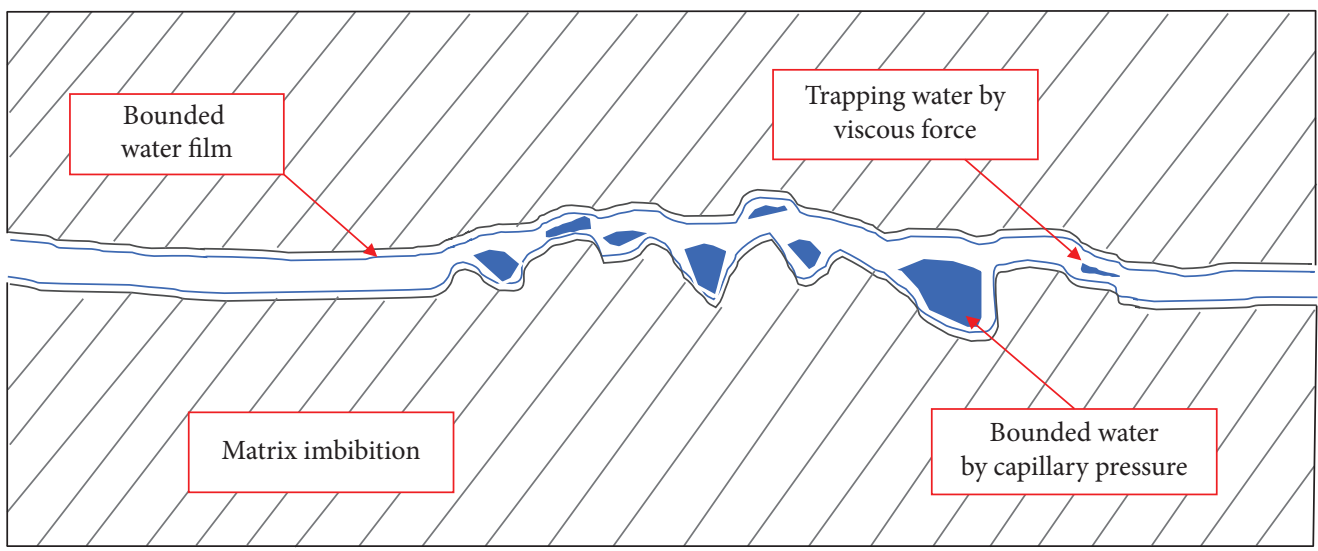

FIGURE 17: Fracture surface retention and viscous trapping in the fracture.

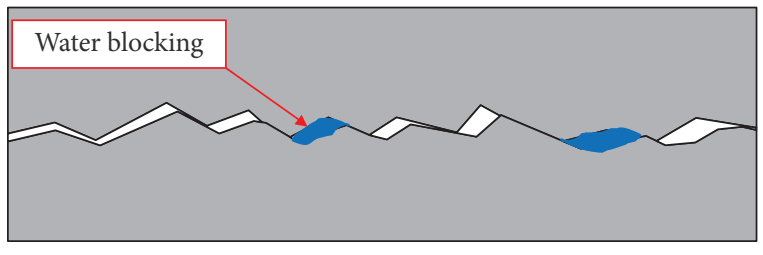

Figure 18: Fracture "locking."

6.2. Retention Rules of Fracturing Fluid. Based on the above research, we could see that the mechanism of fluid retention mainly includes gravity retention in the primary fracture, which is related to the fracture aperture. Surface-bound water film, fracture closure "locking," and viscous trapping dominate in the secondary fracture. Surface capillary retention, surface-bound water film, and matrix pore imbibition are key control factors of fluid retention in the microcracks. Retention is divided into fracture volume-dependent retention and surface-related retention. The fluid retained in fractures may be driven out owing to volume-dependent retention, whereas fluid trapped due to surface-related retention is difficult to drive out. The aperture of the primary fracture is greater than $0.9 \mathrm{~mm}$. When the aperture is sufficiently large, the fluid retention is mainly affected by the fracture aperture and the gas drive pressure. However, roughness and tortuosity have minimal effects. When the aperture reaches the scale range of the secondary fracture (aperture between 0.25 and $0.7 \mathrm{~mm}$ ), the contact of the microconvex body on the rough fracture surface will reduce the drainage of liquid. The roughness and tortuosity of the fracture play an important role in the retention of the fracturing fluid in a secondary fracture. With a further reduction in the fracture aperture, the scale range of a microcrack (less than $0.2 \mathrm{~mm}$ ) is gradually reached. The contact area between the two joints increases.

The retention rate of the fracturing fluid in the primary fracture is approximately $30 \%$ owing to the surface tension of the proppant, wettability, and gravity [20]. The difference in the retention rate in the primary fracture between this study and previous research is attributed to the following reasons. (1) The fracture area is $64.5 \mathrm{~cm}^{2}$, and the material is shale outcrop in this study. The fracture area is $625 \mathrm{~cm}^{2}$, and the material is glass plate in Parmer's study. (2) A proppant was not used in the primary fracture of this study, in which the retention rate of liquid in the primary fracture may be overestimated. However, the subsidence of the proppant in the main fracture is typically considered.

Flowback is required in tight reservoirs during the later stages of fracturing. During the process of flowback, the fracturing fluid and gas are produced at the same time. The experiment simulated two stages of liquid flowback. The first stage relies on the elastic energy of the rock itself to drain the liquid in fractures. In the second stage, the incoming gas provides the power for the drainage of the liquid. The free gas generated during the formation of the fracture network can be produced and consumed continuously when the fracturing fluid is discharged in the initial stage. The gas was injected after a certain period of drainage in this experiment. When the gas-dominant channel was formed in the fracture, the capability of driving fluid dropped dramatically. Once this "breakthrough" occurred during flowback, it could aggravate the retention in fractures. The discharge of liquid is mainly dependent on the elastic energy of formation and liquid expansion without gas providing the energy of displacement.

The nozzle size can be adjusted to control the flowback speed during the period of loading water recovery. "Breakthrough" should be avoided as much as possible owing to the damage to the formation. The drainage rate represents the discharge velocity of the fracturing fluid, and it is high under large apertures in the initial stage. The presence of gas has a significant effect on the drainage rate. Development of the tight reservoir is efficient with high reservoir quality and a complex network.

6.3. Application of FFR. The engineering parameter that corresponds to the retention rate of fracturing fluid is the flowback rate in the field. A low postfracturing flowback rate for efficient and fracture-developed wells in tight reservoirs exist. Fracturing fluid entering the formation gradually diffuses into the deep part of the matrix. Yang et al. found that the capacity for spontaneous imbibition is positively correlated with the content and type of clay mineral. The 
TABLE 5: FFR mechanisms.

\begin{tabular}{lcc}
\hline Retention mechanism & Controlling factor & Favorable condition \\
\hline $\begin{array}{l}\text { Surface capillary retention } \\
\text { Surface-bound water film }\end{array}$ & Wettability, surface roughness & Lurface dryness, liquid surface properties \\
Matrix pore imbibition & Physical properties, liquid type, clay and ion content & Small pores, wetting liquids, high clay/ion content \\
Fracture closure "locking" & Contact area, fracture aperture, roughness, stress & Large contact area/stress, high roughness, small aperture \\
Gravity retention & Liquid viscosity, fracture aperture, roughness, & High viscous force, large aperture \\
Viscous trapping & fracture height & Small aperture and pressure, high viscosity \\
\hline
\end{tabular}

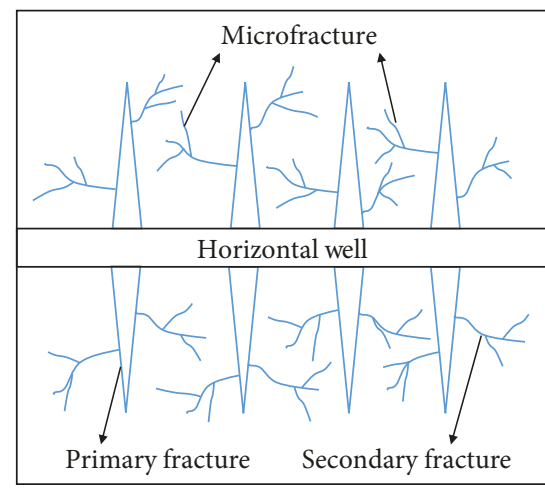

(a)

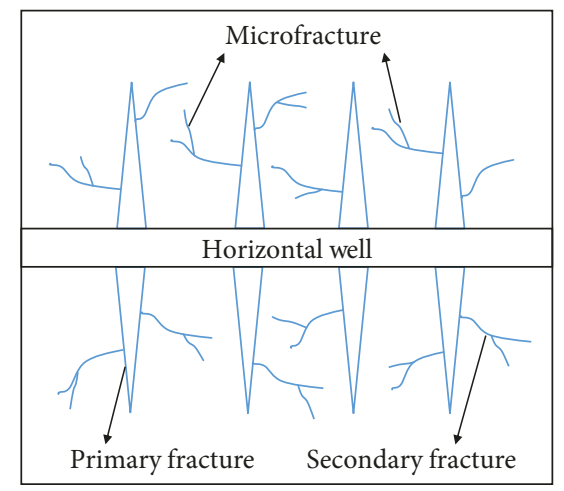

(b)

FIGURE 19: Comparison of fractures: (a) complex fractures and (b) simple fractures (modified from Ghanbari and Dehghanpour [24]).

volume of imbibition is larger than its pore volume [9]. Hu et al.'s research showed that the retention of fracturing fluid in organic pores is directly related to the mineral types. The thermal maturity of an organic matter and the roughness of the pores are closely related to the retention [33]. The reduced flowback rate results from the surface-bound water film, surface retention by capillary force, and matrix imbibition. A high retention rate is related to great matrix imbibition, rich organic matter content, and complex organic pore. The retention rate can reflect the reservoir property.

Multistage hydraulic fracturing usually forms multistage fractures. A large amount of fracturing fluid is injected into the formation to create fractures, accompanied by a large amount of free gas. When the fracture size is less than $0.1 \mathrm{~mm}$ (microcrack), the fluid entering the microcrack cannot easily flow back. When the fracture size is between 0.2 and $0.9 \mathrm{~mm}$ (secondary fracture), the fluid entering the secondary fracture can flow back partially. When the fracture size is larger than $0.9 \mathrm{~mm}$ (hydraulic fracture), the fluid entering the primary fracture is likely to flow back. A high retention rate is related to the high frequency of secondary fractures and microcracks formed in the fracture system and the high roughness and tortuosity. A good fracturing effect is related to good connectivity between the matrix and fracture, as shown in Figure 19. Compared with simple fractures, the complex fractures have more secondary and microfractures, larger stimulated volume, and more matrix imbibition. Therefore, they have a lower flowback rate and a higher initial gas production rate.

\section{Conclusions}

We can draw the following conclusions from the above results.

(1) Fluid is mainly retained in the fracture system, and secondary fractures and microcracks play a major role in fluid retention. The retention of fracturing fluid decreases with an increase in the fracture aperture. The retention rate of fluid will increase with the small aperture, high roughness, high tortuosity, and high matrix imbibition

(2) Gas drive can cause abrupt changes in the drainage mass and rate. When gas drive is not performed, the drainage rate decreases smoothly and the drainage mass increases steadily. After the gas drive, sufficient gas volume is related to improving drainage rate and mass. As the gas creates a "breakthrough" phenomenon in the fractures, the increase in the drainage mass tends to plateau off

(3) Liquid retention in the primary fracture is mainly affected by the fracture aperture. Liquid retention in the secondary fracture is mainly affected by the surface roughness and tortuosity. The liquid retention in the microfractures is mainly affected by the fracture aperture and surface roughness. The retained fluid related to the volume may be driven out, whereas that related to the surface is difficult to drive out 


\section{Nomenclature}

$R_{\mathrm{q}}: \quad$ Mean square roughness $(\mu \mathrm{m})$

$R_{\mathrm{a}}$ : Arithmetic mean deviation of roughness $(\mu \mathrm{m})$

$R_{\mathrm{v}}$ : Maximum height drop of roughness $(\mu \mathrm{m})$

$\Sigma M$ : Total injection mass (g)

$M_{\mathrm{f}}$ : Drainage mass $(\mathrm{g})$

$M_{\mathrm{m}}$ : Matrix imbibition (g)

$M_{\mathrm{s}}$ : Surface-bound water film retention (g)

$M_{\mathrm{c}}$ : Capillary retention (g)

$M_{\mathrm{v}}$ : Viscous retention (g)

$M_{\mathrm{l}}$ : Fracture "lock" retention (g)

$R: \quad$ Retention rate (\%).

\section{Data Availability}

The data used to support the findings of this study are available from the corresponding author upon request.

\section{Conflicts of Interest}

The authors declare that they have no conflicts of interest.

\section{Acknowledgments}

This work was supported by the National Science and Technology Major Project (grant number 2017ZX05039-004), the National 973 Program (grant number 2015CB250903), and the National Natural Science Foundation of China (grant number 51604287). We will also like to thank Bruker in China for measuring the rock surface morphology.

\section{References}

[1] G. E. King, "Hydraulic fracturing 101: what every representative, environmentalist, regulator, reporter, investor, university researcher, neighbor and engineer should know about estimating Frac risk and improving Frac performance in unconventional gas and oil wells," in SPE Hydraulic Fracturing Technology Conference, p. 80, The Woodlands, TX, USA, 2012.

[2] B. M. Robinson, S. A. Holditch, and W. S. Whitehead, "Minimizing damage to a propped fracture by controlled flowback procedures," Journal of Petroleum Technology, vol. 40, no. 6, pp. 753-759, 2013.

[3] D. M. Willberg, N. Steinsberger, R. Hoover, R. J. Card, and J. Queen, "Optimization of fracture cleanup using flowback analysis," in SPE Rocky Mountain Regional/Low-Permeability Reservoirs Symposium, p. 13, Denver, CO, USA, 1998.

[4] J. D. Weaver, N. C. Schultheiss, and F. Liang, "Fracturing fluid conductivity damage and recovery efficiency," in SPE European Formation Damage Conference \& Exhibition, p. 12, Noordwijk, The Netherlands, 2013.

[5] P. Bedrikovetsky, A. S. L. Vaz, C. J. A. Furtado, and A. R. Serra de Souza, "Formation-damage evaluation from nonlinear skin growth during coreflooding," SPE Reservoir Evaluation \& Engineering, vol. 14, no. 2, pp. 193-203, 2013.

[6] H. Son, H. Kim, G. Lee, J. Kim, and W. Sung, "Enhanced oil recovery using nanoparticle-stabilized oil/water emulsions," Korean Journal of Chemical Engineering, vol. 31, no. 2, pp. 338-342, 2014.
[7] L. He, Y. Chen, L. Ren, J. Li, and L. Liu, "Synergistic management of flowback and produced waters during the upstream shale gas operations driven by non-cooperative stakeholders," Journal of Natural Gas Science and Engineering, vol. 52, pp. 591-608, 2018.

[8] H. B. Lee, I. W. Yeo, and K. K. Lee, "The modified Reynolds equation for non-wetting fluid flow through a rough-walled rock fracture," Advances in Water Resources, vol. 53, no. 1, pp. 242-249, 2013.

[9] L. Yang, H. Ge, Y. Shen et al., "Experimental research on the shale imbibition characteristics and its relationship with microstructure and rock mineralogy," in SPE Asia Pacific Unconventional Resources Conference and Exhibition, p. 10, Brisbane, Australia, 2015.

[10] B. Roychaudhuri, T. T. Tsotsis, and K. Jessen, "An experimental investigation of spontaneous imbibition in gas shales," Journal of Petroleum Science \& Engineering, vol. 111, no. 11, pp. 87-97, 2013.

[11] J. Li, W. Yu, D. Guerra, and K. Wu, "Modeling wettability alteration effect on well performance in Permian basin with complex fracture networks," Fuel, vol. 224, pp. 740-751, 2018.

[12] Y. Shen, H. Ge, C. Li et al., "Water imbibition of shale and its potential influence on shale gas recovery-a comparative study of marine and continental shale formations," Journal of Natural Gas Science and Engineering, vol. 35, pp. 1121-1128, 2016.

[13] C. A. Ehlig-Economides and M. J. Economides, "Water as proppant," in SPE Annual Technical Conference and Exhibition, p. 8, Denver, CO, USA, 2011.

[14] M. Mcclure, "The potential effect of network complexity on recovery of injected fluid following hydraulic fracturing," in SPE Unconventional Resources Conference, p. 19, The Woodlands, TX, USA, 2014.

[15] M. Wang, Y. F. Chen, G. W. Ma, J. Q. Zhou, and C. B. Zhou, "Influence of surface roughness on nonlinear flow behaviors in 3D self-affine rough fractures: lattice Boltzmann simulations," Advances in Water Resources, vol. 96, pp. 373388, 2016.

[16] G. Rong, J. Yang, L. Cheng, and C. Zhou, "Laboratory investigation of nonlinear flow characteristics in rough fractures during shear process," Journal of Hydrology, vol. 541, pp. 1385-1394, 2016.

[17] T. Babadagli, X. Ren, and K. Develi, "Effects of fractal surface roughness and lithology on single and multiphase flow in a single fracture: an experimental investigation," International Journal of Multiphase Flow, vol. 68, pp. 40-58, 2015.

[18] J. Tang, K. Wu, B. Zeng et al., "Investigate effects of weak bedding interfaces on fracture geometry in unconventional reservoirs," Journal of Petroleum Science and Engineering, vol. 165, pp. 992-1009, 2018.

[19] M. Wang and J. Y. Leung, "Numerical investigation of fluidloss mechanisms during hydraulic fracturing flow-back operations in tight reservoirs," Journal of Petroleum Science \& Engineering, vol. 133, pp. 85-102, 2015.

[20] J. Parmar, H. Dehghanpour, and E. Kuru, "Displacement of water by gas in propped fractures: combined effects of gravity, surface tension, and wettability," Journal of Unconventional Oil and Gas Resources, vol. 5, pp. 10-21, 2014.

[21] Y. Shen, H. Ge, M. Meng, Z. Jiang, and X. Yang, "Effect of water imbibition on shale permeability and its influence on gas production," Energy \& Fuels, vol. 31, no. 5, pp. 49734980, 2017. 
[22] J. Cai, W. Wei, X. Hu, R. Liu, and J. Wang, "Fractal characterization of dynamic fracture network extension in porous media," Fractals, vol. 25, no. 2, article 1750023, 2017.

[23] Y. Liu, J. Y. Leung, R. Chalaturnyk, and C. J. J. Virues, "Fracturing fluid distribution in shale gas reservoirs due to fracture closure, proppant distribution and gravity segregation," in SPE Unconventional Resources Conference, p. 21, Calgary, Alberta, Canada, 2017.

[24] E. Ghanbari and H. Dehghanpour, "The fate of fracturing water: a field and simulation study," Fuel, vol. 163, pp. 282294, 2016.

[25] J. Tang and K. Wu, "A 3-D model for simulation of weak interface slippage for fracture height containment in shale reservoirs," International Journal of Solids and Structures, vol. 144-145, pp. 248-264, 2018.

[26] J. Hampton, M. Gutierrez, L. Matzar, D. Hu, and L. Frash, "Acoustic emission characterization of microcracking in laboratory-scale hydraulic fracturing tests," Journal of Rock Mechanics and Geotechnical Engineering, vol. 10, no. 5, pp. 805-817, 2018.

[27] W. Kan, S. Anusarn, and T. Jizhou, "Numerical study of flow rate distribution for simultaneous multiple fracture propagation in horizontal wells," in 50th U.S. Rock Mechanics/ Geomechanics Symposium, p. 7, Houston, TX, USA, 2016.

[28] Y. Fu, H. Dehghanpour, D. O. Ezulike, and R. S. Jones Jr., "Estimating effective fracture pore volume from flowback data and evaluating its relationship to design parameters of multistage-fracture completion," SPE Production \& Operations, vol. 32, no. 4, pp. 423-439, 2017.

[29] M. A. Abbasi, D. O. Ezulike, H. Dehghanpour, and R. V. Hawkes, "A comparative study of flowback rate and pressure transient behavior in multifractured horizontal wells completed in tight gas and oil reservoirs," Journal of Natural Gas Science and Engineering, vol. 17, pp. 82-93, 2014.

[30] J. Q. Zhou, S. H. Hu, S. Fang, Y. F. Chen, and C. B. Zhou, "Nonlinear flow behavior at low Reynolds numbers through rough-walled fractures subjected to normal compressive loading," International Journal of Rock Mechanics and Mining Sciences, vol. 80, pp. 202-218, 2015.

[31] Y. F. Chen, J. Q. Zhou, S. H. Hu, R. Hu, and C. B. Zhou, "Evaluation of Forchheimer equation coefficients for nonDarcy flow in deformable rough-walled fractures," Journal of Hydrology, vol. 529, pp. 993-1006, 2015.

[32] Z. Zhang and J. Nemcik, "Fluid flow regimes and nonlinear flow characteristics in deformable rock fractures," Journal of Hydrology, vol. 477, no. 1, pp. 139-151, 2013.

[33] Y. Hu, D. Devegowda, A. Striolo et al., "The dynamics of hydraulic fracture water confined in nano-pores in shale reservoirs," Journal of Unconventional Oil and Gas Resources, vol. 9, pp. 31-39, 2015. 

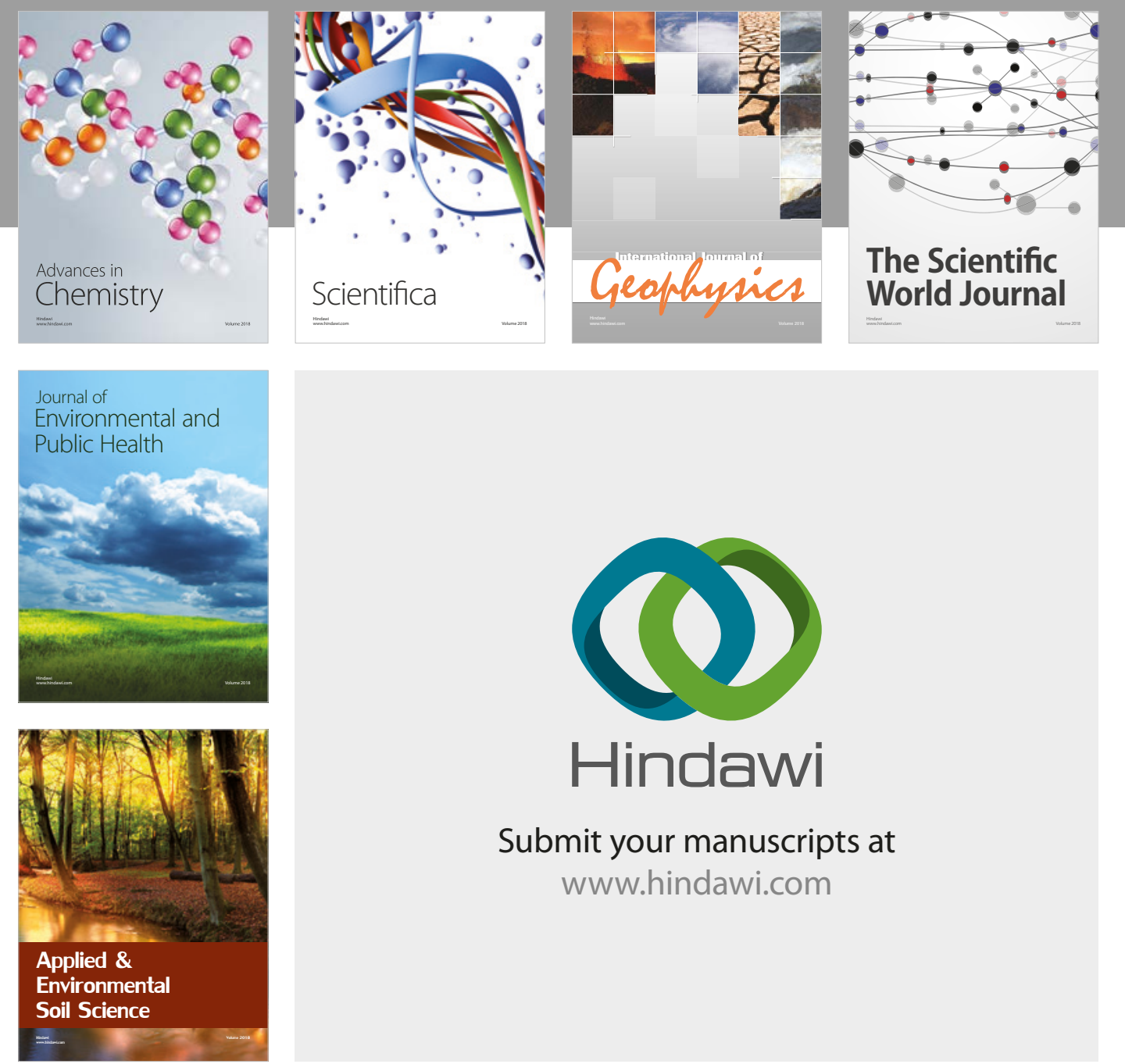

The Scientific

\section{World Journal}
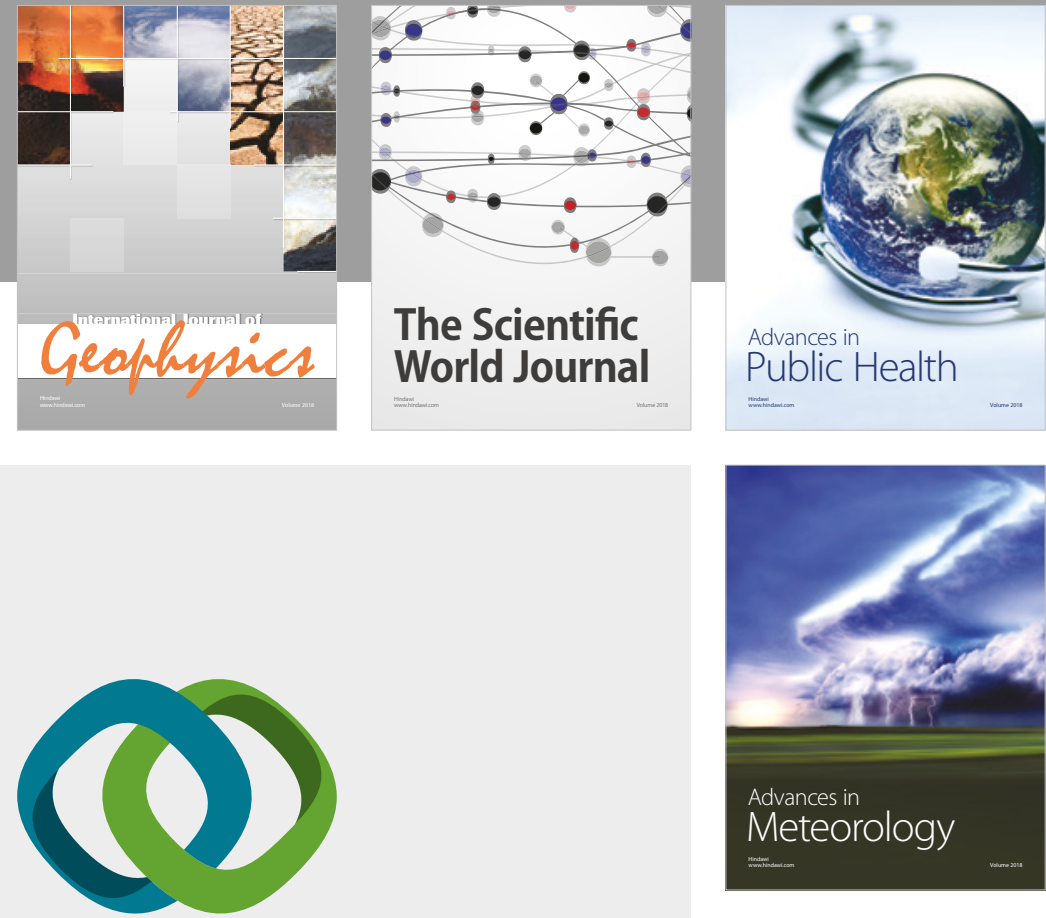

Advan

Public Health

\section{Hindawi}

Submit your manuscripts at

www.hindawi.com
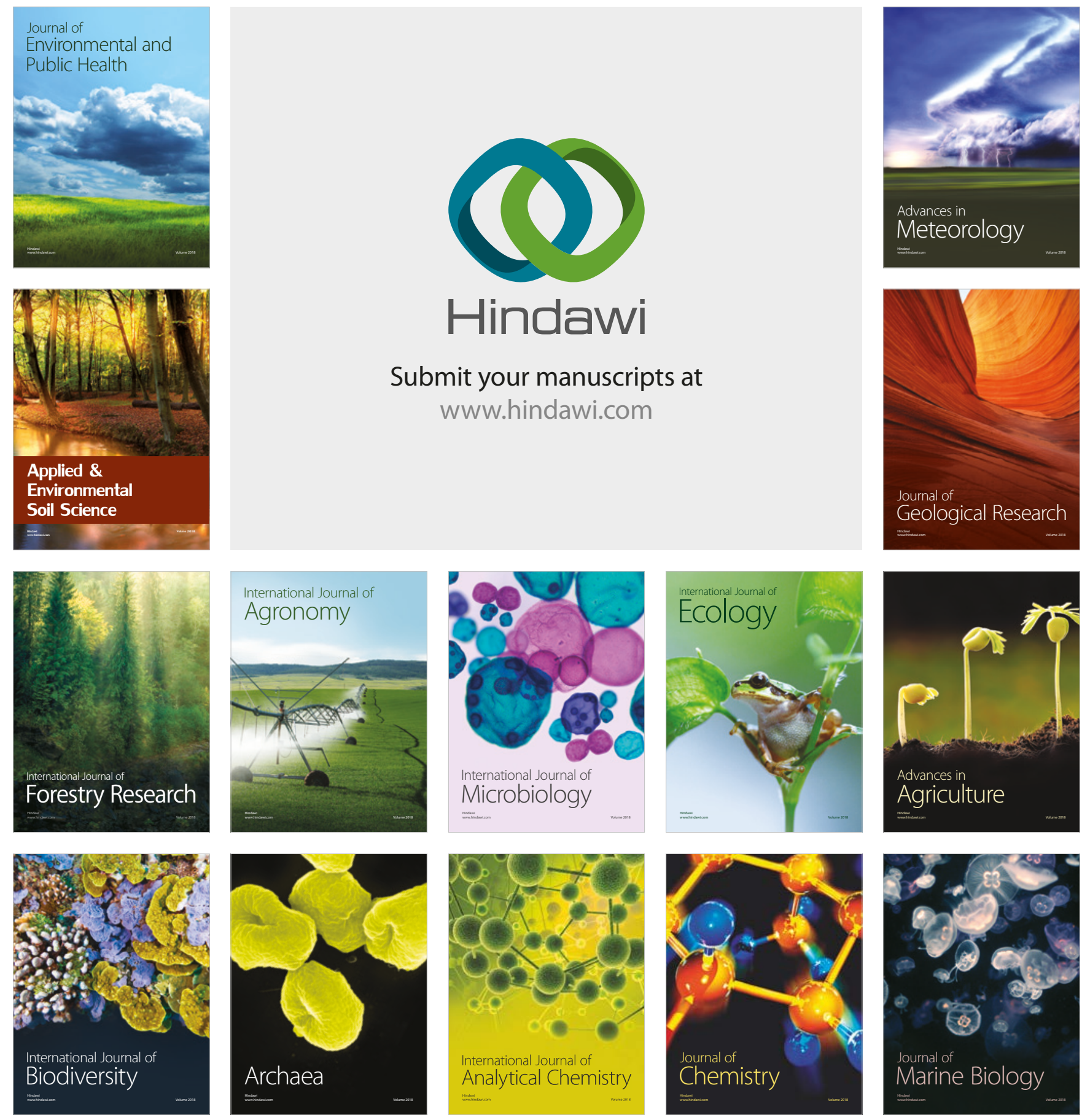